Supporting Information for

\title{
Fragmentation of Lignin Samples with Commercial Pd/C under Ambient Pressure of Hydrogen
}

\author{
Fang Gao, Jonathan D. Webb, Hagit Sorek, David E. Wemmer and John F. Hartwig* \\ Department of Chemistry, University of California, Berkeley, California 94720 1460, United States \\ E-mail: jhartwig@berkeley.edu
}

\section{Table of Contents}

General experimental details

S4

Characterizations of resinol and phenylcoumaran model compounds

General procedure for fragmentation of lignin model compounds without hydrogen $\quad$ S7

Competition experiment: fragmentation of a 1:1 mixture of 2-phenoxy-1-phenylethan-1ol and 2-(2-methoxyphenoxy)-1-phenylethan-1-one catalyzed by Pd/C (Eq 4)

Time profile analysis: fragmentation of 2-phenoxy-1-phenylpropane-1,3-diol catalyzed by $\mathrm{Pd} / \mathrm{C}$ catalyst (Figure 1 )

Figure S1. HSQC spectra of the aromatic regions of lignin samples isolated from $M$. Giganteus through ethanol-, acetone-, and dixoane-solvolysis

The procedure for $\mathrm{Pd} / \mathrm{C}$ catalyzed fragmentation of the isolated acetone-solv lignin sample from M. Giganteus under hydrogen free conditions

Figure S2. HSQC spectrum of the degradation product of acetone-solv lignin with $\mathrm{Pd} / \mathrm{C}$ without added $\mathrm{H}_{2}$ in comparison to the acetone-solv lignin from M. Giganteus (aromatic region)

S15

The procedure for hydrogenative treatment of dioxanesolv lignin samples from $M$. Giganteus

The procedure for $\mathrm{Pd} / \mathrm{C}$ catalyzed fragmentation of this pretreated dioxanesolv lignin sample under hydrogen free conditions (Scheme 3)

S16 
Figure S3. HSQC spectra of the degraded material after fragmentation treatment in comparison with the hydrogenatively treated acetonesolv lignin (aliphatic region) S17 General procedure for fragmentation of lignin samples catalyzed by $\mathrm{Pd} / \mathrm{C}$ under an atmospheric pressure of hydrogen

Procedure for the fragmentation of synthetic lignin catalyzed by $\mathrm{Pd} / \mathrm{C}$ under an atmospheric pressure of hydrogen (Scheme 4)

Figure S4. HSQC spectrum of synthetic lignin and the linkage analysis

S20

Figure S5. HSQC spectra of the degraded synthetic lignin and of the material obtained from the control experiment (aliphatic and oxygenated region)

S21

Figure S6. HSQC spectra of the degraded synthetic lignin and of the material obtained from the control experiment (aromatic region)

S23

The procedure for $\mathrm{Pd} / \mathrm{C}$ catalyzed fragmentation of acetonesolv lignin under an atmospheric pressure of hydrogen (Figure 2 and Entry 1, Table 2)

S23

Figure S7. GPC traces of 1) acetonesolv lignin, 2) material obtained from the control experiment, 3) degraded acetonesolv lignin after the fragmentation reaction and 4) overlay with degraded material from fragmentation of hydrogenatively treated acetonesolv lignin under hydrogen free condition

S24

Table S1. Screening of the BASF heterogeneous catalyst kit for fragmentation of acetonesolv lignin under $15 \mathrm{psi}$ of $\mathrm{H}_{2}$

$\mathrm{S} 25$

The procedure for fragmentation of ethanolsolv lignin catalyzed by $\mathrm{Pd} / \mathrm{C}$ under an atmospheric pressure of hydrogen (Figure 2 and Entry 2, Table 2)

S25

Figure S8. HSQC spectra of the degraded ethanolsolv lignin in comparison with the material obtained from the control experiment (aliphatic region)

S26

Figure S9. GPC graphs of 1) ethanolsolv lignin, 2) material obtained from the control experiment and 3) degraded ethanolsolv lignin after the fragmentation reaction

S27

The procedure for $\mathrm{Pd} / \mathrm{C}$ catalyzed fragmentation of dioxanesolv lignin under an atmospheric pressure of hydrogen (Figure 2 and Entry 3, Table 2)

Figure S10. GPC trace of 1) dioxanesolv lignin, 2) material obtained from the control 
experiment and 3) degraded dioxanesolv lignin after the fragmentation reaction

The procedure for $\mathrm{Pd} / \mathrm{C}$ catalyzed fragmentation of dioxanesolv pine lignin under an atmospheric pressure of hydrogen (Figure 2 and Entry 4, Table 2)

S28

Figure S11. HSQC spectra of the degraded dioxanesolv pine lignin in comparison with the material obtained from the control experiment (aromatic region)

S29

Figure S12. GPC graphs of 1) material obtained from the control experiment and 2) degraded dioxanesolv pine lignin

S30

Scheme S1. Fragmentation of the phenylcoumarin model compound with and without 15 psi of hydrogen

Scheme S2. Fragmentation of the resinol model compound with and without 15 psi of hydrogen

General procedure for the gram-scale catalytic fragmentation of lignin samples under an atmospheric pressure of hydrogen with reduced loading of $\mathrm{Pd} / \mathrm{C}$

S32

Figure S13. GPC graphs of gram-scale fragmentations of 1) acetonesolv lignin, 2) ethanolsolv lignin, 3) dioxanesolv lignin and 4) dioxanesolv pine lignin

S33

Table S2. Viscosity measurement of dioxansolv lignin blended with various amount of dioxane at 22 and $50{ }^{\circ} \mathrm{C}$

S34

Table S3. Viscosity measurement of dioxansolv lignin blended with various renewable solvents S34

${ }^{1} \mathrm{H}$ and ${ }^{13} \mathrm{C}$ NMR spectrum S35

References

S39 


\section{General experimental details}

\section{Equipment and methods}

All air-sensitive manipulations were conducted in a nitrogen-filled glovebox or by standard Schlenk technique under nitrogen. All glassware was heated in an oven and cooled under an inert atmosphere prior to use.

GC analyses were obtained on an Agilent 7890 Gas Chromatograph equipped with an HP-5 $30 \mathrm{~m}$ x $0.20 \mathrm{~mm}$ ID x $0.33 \mu \mathrm{m}$ capillary column (Agilent) and an FID detector.

The following GC oven temperature programs were used: A) $100{ }^{\circ} \mathrm{C}$ hold for $3 \mathrm{~min}$, ramp $40{ }^{\circ} \mathrm{C} / \mathrm{min}$ to a final temperature of $300^{\circ} \mathrm{C}$, and hold for $2.5 \mathrm{~min}$; B) $35^{\circ} \mathrm{C}$ hold for $2 \mathrm{~min}$, ramp $45^{\circ} \mathrm{C} / \mathrm{min}$ to a final temperature of $300^{\circ} \mathrm{C}$, and hold for $2 \mathrm{~min}$. Helium was used as a carrier gas, with a constant column flow of $5.6 \mathrm{ml} / \mathrm{min}$ (program A) or 6.6 $\mathrm{ml} / \mathrm{min}$ (program B). The injector temperature was held at $250^{\circ} \mathrm{C}$ (program A) or $300{ }^{\circ} \mathrm{C}$ (program B). All GC-yields were obtained by establishing response factors of authentic samples either from commercial sources or chemical synthesis.

GC-MS analyses were obtained on an Agilent 6890-N Gas Chromatograph equipped with an HP-5 $30 \mathrm{~m} \times 0.25 \mathrm{~mm} \times 0.25 \mu \mathrm{m}$ capillary column (Agilent). The GC was directly interfaced to an Agilent 5973 mass selective detector (EI, $70 \mathrm{eV}$ ). The following GC oven temperature programs were used: A) $50{ }^{\circ} \mathrm{C}$ hold for $2 \mathrm{~min}$, ramp $40{ }^{\circ} \mathrm{C} / \mathrm{min}$ to a final temperature of $300^{\circ} \mathrm{C}$, and hold for $2 \mathrm{~min}$; B) $100^{\circ} \mathrm{C}$ hold for $3 \mathrm{~min}$, ramp $40{ }^{\circ} \mathrm{C} / \mathrm{min}$ to a final temperature of $300^{\circ} \mathrm{C}$, and hold for $2.5 \mathrm{~min}$. Helium was used as a carrier gas, with a constant column flow of $1 \mathrm{ml} / \mathrm{min}$. The injector temperature was held constant at $250^{\circ} \mathrm{C}$.

The NMR spectra were acquired on a Bruker Avance 600-MHz spectrometer equipped with a CPTXI cryoprobe. Lignin and degraded products were dissolved in deuterated dimethyl sulfoxide (DMSO- $\left.d_{6}\right)$; the solvent peak was used as an internal reference $\left(\delta_{\mathrm{C}}\right.$ $\left.39.5, \delta_{\mathrm{H}} 2.49 \mathrm{ppm}\right) .{ }^{13} \mathrm{C}-{ }^{1} \mathrm{H}$ HSQC experiments had the following parameters: acquired from 12 to 0 ppm in F2 (1H) by using 2048 data points for an acquisition time (AQ) of $143 \mathrm{~ms}, 210-0$ ppm in F1 (13C) by using 256 increments (F1 acquisition time $4.0 \mathrm{~ms}$ ) of 48 scans with a $1 \mathrm{~s}$ interscan delay (D1). Squared cosine-bell apodization function was applied in both dimensions. HSQC cross-peaks were assigned by combining the results 
and comparing them with the literature. ${ }^{1}$ A semi-quantitative analysis of the HSQC crosspeak intensities was performed in the aliphatic oxygenated region, interunit linkages were estimated from $\mathrm{C} \alpha-\mathrm{H} \alpha$ correlations and the relative abundance of side chains involved in interunit linkages was calculated (with respect to total side chains). Volume integration of peaks in HSQC plots was accomplished using Bruker's TopSpin 3.0 software. Other Bruker implementations of 2D NMR experiments were used for structural elucidation and assignment authentication.

Molecular weight was analyzed by gel permeation chromatography (GPC). Lignin samples were dissolved in tetrahydrofuran (THF, $1 \mathrm{mg} / \mathrm{mL}$ ) and analyzed on a GPC 50 Plus system (Agilent Technologies, Santa Clara, CA, USA) with a UV detector and autosampler. All lignins prepared in this study were soluble in THF at $1 \mathrm{mg} / \mathrm{mL}$. The columns used were a series of two $300 \mathrm{~mm} \AA \sim 7.5 \mathrm{~mm}$ i.d., $3 \mu \mathrm{m}$, MesoPore, with a 50 $\mathrm{mm} \AA \sim 7.5 \mathrm{~mm}$ i.d. guard column of the same material (Agilent Technologies). Samples were eluted at $30{ }^{\circ} \mathrm{C}$ with $1 \mathrm{~mL} / \mathrm{min} \mathrm{THF}$ and detected at $280 \mathrm{~nm}$. The system was calibrated using polystyrene samples (EasiVial PS-L) in the range of Mp 38 640-162 Da (Agilent Technologies). Molecular weight at peak top (Mp), number-averaged molecular weight $(\mathrm{Mn})$, weight-averaged molecular weight $(\mathrm{Mw})$, and polydispersity $(\mathrm{Mw} / \mathrm{Mn})$ were determined by the Cirrus software (Agilent Technologies).

Viscosity was measured with the LVDV-II+P model viscometer from Brookfield Engineering Laboratories Inc, which was equipped with a SC4-15 spindle and a SCA$7 R(P)$ sample chamber $\left(3.7 \mathrm{~cm}^{3}\right.$ in volume). Samples of at least $3.5 \mathrm{~mL}$ in volume were transferred into the chamber with a measuring pipette. Viscosity values were directly recorded from the display panel after the spindle was steadily rotating at the chosen rpm (50-200 rpm for the measurement performed in this study); the \% torque values were kept above 10 for all measurements.

\section{Solvents and reagents}

$\mathrm{Ni} / \mathrm{C}$ (3 wt \% of Ni metal) was prepared according to the literature procedure ${ }^{2}$ and stored at $-30{ }^{\circ} \mathrm{C}$ in a glovebox before use. $\mathrm{Ni} / \mathrm{SiO}_{2} / \mathrm{Al}_{2} \mathrm{O}_{3}$ (20 wt \% of $\mathrm{Ni}$ metal) was purchased from Aldrich, stored in a glovebox and used as received. $\mathrm{Pd} / \mathrm{C}$ (10 wt \% of Pd metal) was purchased from Aldrich, stored in a glovebox and used as received. $\mathrm{Pd} / \mathrm{Al}_{2} \mathrm{O}_{3}(10 \mathrm{wt} \%$ of 
$\mathrm{Pd}$ metal) and $\mathrm{Pd} / \mathrm{BaSO}_{4}(10 \mathrm{wt} \%$ of $\mathrm{Pd}$ metal) were purchased from Aldrich, stored in a glovebox and used as received. $\mathrm{Ru} / \mathrm{C}\left(5 \mathrm{wt} \%\right.$ of $\mathrm{Ru}$ metal) and $\mathrm{Ru} / \mathrm{Al}_{2} \mathrm{O}_{3}$ (5 wt \% of $\mathrm{Ru}$ metal) were purchased from Aldrich, stored in a glovebox and used as received. $\mathrm{Rh} / \mathrm{C}$ (5 wt \% of Rh metal) was purchased from Aldrich, stored in a glovebox and used as received. $\mathrm{Pt} / \mathrm{C}\left(10 \mathrm{wt} \%\right.$ of $\mathrm{Pt}$ metal) and $\mathrm{Pt} / \mathrm{Al}_{2} \mathrm{O}_{3}(5.0 \mathrm{wt} \%$ of $\mathrm{Pt}$ metal) were purchased from Aldrich, stored in a glovebox and used as received. The BASF heterogeneous catalyst kit was purchased from Strem (catalog number 96-6717), stored in a glovebox and used as received. Anhydrous $m$-xylene was purchased from Aldrich and used as received. Anhydrous 1,4-dioxane was purchased from Acros and used as received. Both solvents were stored and used under a nitrogen atmosphere in a glovebox. 2methyltetrahydrofuran (reagent grade) and $\gamma$-valerolactone (reagent grade) were purchased from Aldrich and used as received. Phenol (reagent grade) was purchased from Fisher and used as received. Acetophenone (analytical standard) was purchased from Aldrich and used as received. Ethylbenzene (analytical standard) was purchased from Aldrich and used as received. Propiophenone (analytical standard) was purchased from Aldrich and used as received. Guaiacol (natural, >99\%) was purchased from Aldrich and used as received. 1,2-Dimethoxy-4-ethylbenzene (>95\%) was purchased from Combiblocks and used as received. 1,2-Dimethoxy-4-propylbenzene was purchased from Oakwood products and used as received. 4-Ethylguaiacol (analytical standard) was purchased from Aldrich and used as received. 4-Ethylphenol (analytical standard) was purchased from Aldrich and used as received. 2-Methoxy-4-propylphenol (>99\%) was purchased from Aldrich and used as received. 4-(3-Hydroxypropyl)-2,6-dimethoxyphenol was purchased from Ark Pharm and used as received. Dihydroconiferyl alcohol (95\%) was purchased from Combi-blocks and used as received. Hydrogen (industrial grade, 99.95\%) was purchased from Praxair and was used as received. 2-Phenoxy-1phenylethan-1-one (>97\%) was purchased from TCI-America and used as received. 2Phenoxy-1-phenylethan-1-ol and 2-(2-methoxyphenoxy)-1-phenylethan-1-ol were prepared according to the previously reported procedure. ${ }^{3} 2$-Phenoxy-1-phenylpropane1,3-diol was prepared according to the previously reported procedure. ${ }^{4} 1-(3,4-$ Dimethoxyphenyl)-2-(2-methoxyphenoxy)propane-1,3-diol was prepared according to the previously reported procedure. ${ }^{5} \quad$ 1-(4-Hydroxy-3-methoxyphenyl)-2-(2- 
methoxyphenoxy)propane-1,3-diol was prepared according to the previously reported procedure. $^{6}$ 1,4-Bis(4-methoxyphenyl)tetrahydro- $1 H, 3 H$-furo[3,4-c]furan (resinol model compound) was prepared by adapting a synthetic sequence described in a previous publication. $^{7} \quad$ (2-(4-Methoxyphenyl)-2,3-dihydrobenzofuran-3-yl)methanol (phenylcoumaran model compound) was prepared by adapting a synthetic sequence described in a previous publication. ${ }^{8}$ The synthetic lignin was obtained from the M. C. Chang group at UC Berkeley and prepared by a procedure adapted from a previous publication. ${ }^{9}$ Organosolv lignins derived from M. Giganteus and pine trees were obtained from the analytical lab headed by Stefan Bauer at the Energy Biosciences Institute of UC Berkeley; the preparation of these lignin samples was described in a previous publication, and the characterizations with 2D NMR and GPC experiments of these samples were provided in this study. ${ }^{10}$

\section{Characterizations of resinol and phenylcoumaran model compounds}

Phenylcoumaran model compound: (2-(4-Methoxyphenyl)-2,3-dihydrobenzofuran-3-

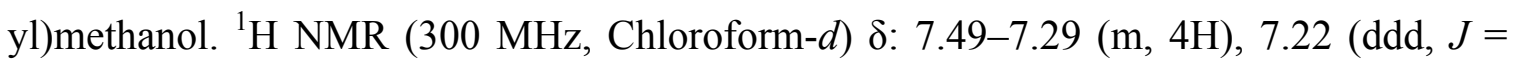
7.7, 4.4, $1.3 \mathrm{~Hz}, 2 \mathrm{H}), 7.05-6.88(\mathrm{~m}, 2 \mathrm{H}), 5.63$ (d, $J=6.0 \mathrm{~Hz}, 1 \mathrm{H}), 4.00-3.84(\mathrm{~m}, 2 \mathrm{H})$, $3.71(\mathrm{~d}, J=1.2 \mathrm{~Hz}, 3 \mathrm{H}), 3.57(\mathrm{q}, J=5.9 \mathrm{~Hz}, 1 \mathrm{H}), 2.10(\mathrm{~s}, 1 \mathrm{H}) ;{ }^{13} \mathrm{C}$ NMR $(125 \mathrm{MHz}$, Chloroform- $d$ ) $\delta: 159.9,141.7,129.0,128.6,127.9,126.3,125.5,124.5,120.7,109.6$, 86.6, 66.9, 64.4, 53.5; HRMS (ESI) calc'd (M+H) 257.1172, found 257.1197.

Resinol model compound: 1,4-Bis(4-methoxyphenyl)tetrahydro- $1 H, 3 H$-furo[3,4c]furan. ${ }^{1} \mathrm{H}$ NMR (300 MHz, Chloroform- $d$ ) $\delta:$ 7.36-7.25 (m, 4H), 6.98-6.86 (m, 4H), $4.78(\mathrm{~d}, J=4.0 \mathrm{~Hz}, 2 \mathrm{H}), 4.35-4.18(\mathrm{~m}, 2 \mathrm{H}), 3.89(\mathrm{dd}, J=9.2,3.5 \mathrm{~Hz}, 2 \mathrm{H}), 3.82(\mathrm{~s}, 6 \mathrm{H})$, 3.18-3.05 (m, 2H); ${ }^{13} \mathrm{C}$ NMR (125 MHz, Chloroform-d) $\delta: 159.1,133.0,127.3,113.8$, 85.6, 71.6, 55.2, 54.1; HRMS (ESI) calc'd (M+H) 327.1591, found 327.1573.

\section{General procedure for fragmentation of lignin model compounds without hydrogen}

Reactions were conducted in $4 \mathrm{ml}$ glass vials equipped with Teflon-lined screw caps and Teflon-coated magnetic stir bars $(3 \mathrm{~mm}$ x $8 \mathrm{~mm}$; supplied by Fisher Scientific). The 
reaction vessels were heated in an oil bath; the reaction temperature refers to the temperature of the oil bath. The stirring rate was kept constant at $900 \mathrm{rpm}$ (Magnetic stirrer IKA Ceramag Midi; the stir rate dial was set to 7.5).

In a glovebox, a $4 \mathrm{ml}$ glass vial equipped with a Teflon-coated magnetic stir bar was charged with a heterogeneous metal catalyst (5.0-20 mol\%), a lignin model compound $(0.300 \mathrm{mmol})$ and a magnetic stir bar. Then, a solution of dodecane (10 25 $\mathrm{mg}$, internal standard for GC) in $1.2 \mathrm{~mL} m$-xylene or $p$-cymene/dioxane (1:1 mixture) was added, and the mixture was stirred for $1 \mathrm{~min}$. The vial was sealed with a Teflon-lined screw cap and removed from the glovebox. The vessel was heated in an oil bath at the designated temperature between $120^{\circ} \mathrm{C}$ and $200^{\circ} \mathrm{C}$ for the designated time. The resulting dark black mixture was cooled to room temperature, diluted with ether or ethyl acetate $(1 \mathrm{ml})$, and passed through a short plug of Celite $(2 \mathrm{~cm}$ in length) to remove black solid materials. The resulting clear solution was then subjected to GC and GC/MS analyses. The products have all been reported previously and were identified by comparison of the mass spectra and retention times of the products by GC/MS and $\mathrm{GC}$ with those of authentic compounds that are commercially available or were synthesized.

Fragmentation of 2-phenoxy-1-phenylethan-1-ol catalyzed by Ni/C (Table 1, Entry 1)

The reaction was conducted according to the General Procedure with Ni/C (3.0 wt \%, 29.3 $\left.\mathrm{mg}, 1.50 \times 10^{-2} \mathrm{mmol}, 5.0 \mathrm{~mol} \%\right)$, 2-phenoxy-1-phenylethan-1-ol (64.3 mg, $\left.0.300 \mathrm{mmol}\right)$, dodecane (internal standard for GC) and $m$-xylene $(1.2 \mathrm{ml})$ at $120{ }^{\circ} \mathrm{C}$ for $16 \mathrm{~h}$. GC analysis of the reaction mixture showed that no product formed and $<2 \%$ of the substrate had converted.

Fragmentation of 2-phenoxy-1-phenylethan-1-ol catalyzed by $\mathrm{Ni} / \mathrm{Al}_{2} \mathrm{O}_{3} / \mathrm{SiO}_{2}(\mathrm{Table}$ 1, Entry 2)

The reaction was conducted according to the General Procedure with $\mathrm{Ni} / \mathrm{Al}_{2} \mathrm{O}_{3} / \mathrm{SiO}_{2}(20.0$ $\left.\mathrm{wt} \%, 17.6 \mathrm{mg}, 6.00 \times 10^{-2} \mathrm{mmol}, 20.0 \mathrm{~mol} \%\right)$, 2-phenoxy-1-phenylethan-1-ol (64.3 mg, $0.300 \mathrm{mmol})$, dodecane (internal standard for GC) and $m$-xylene $(1.2 \mathrm{ml})$ at $120{ }^{\circ} \mathrm{C}$ for 16 h. Analysis of the reaction mixture by GC showed that phenol (4\%) and acetophenone $(10 \%)$ formed. 
Fragmentation of 2-phenoxy-1-phenylethan-1-ol catalyzed by Pd/C (Table 1, Entry 3)

The reaction was conducted according to the General Procedure with $\mathrm{Pd} / \mathrm{C}(10.0 \mathrm{wt} \%$, $16.0 \mathrm{mg}, 1.50 \times 10^{-2} \mathrm{mmol}, 5.0 \mathrm{~mol} \%$ ), 2-phenoxy-1-phenylethan-1-ol (64.3 mg, 0.300 mmol), dodecane (internal standard for GC) and $m$-xylene $(1.2 \mathrm{ml})$ at $120{ }^{\circ} \mathrm{C}$ for $16 \mathrm{~h}$. Analysis of the reaction mixture by GC showed that phenol (94\%), acetophenone (93\%) and 2-phenoxy-1-phenylethan-1-one (4\%) formed.

Fragmentation of 2-phenoxy-1-phenylethan-1-ol catalyzed by $\mathrm{Pd} / \mathrm{Al}_{2} \mathrm{O}_{3}$ (Table 1, Entry 4)

The reaction was conducted according to the General Procedure with $\mathrm{Pd} / \mathrm{Al}_{2} \mathrm{O}_{3}(10.0$ wt $\left.\%, 16.0 \mathrm{mg}, 1.50 \times 10^{-2} \mathrm{mmol}, 5.0 \mathrm{~mol} \%\right)$, 2-phenoxy-1-phenylethan-1-ol (64.3 mg, $0.300 \mathrm{mmol})$, dodecane (internal standard for GC) and $m$-xylene $(1.2 \mathrm{ml})$ at $120{ }^{\circ} \mathrm{C}$ for 16 h. Analysis of the reaction mixture by GC showed that phenol (83\%), acetophenone $(87 \%)$ and 2-phenoxy-1-phenylethan-1-one (2\%) formed.

Fragmentation of 2-phenoxy-1-phenylethan-1-ol catalyzed by $\mathrm{Pd}_{\mathbf{B a S O}}$ (Table 1, Entry 5)

The reaction was conducted according to the General Procedure with $\mathrm{Pd} / \mathrm{BaSO}_{4}(10.0$ wt\%, $\left.32.0 \mathrm{mg}, 3.00 \times 10^{-2} \mathrm{mmol}, 10.0 \mathrm{~mol} \%\right)$, 2-phenoxy-1-phenylethan-1-ol (64.3 mg, $0.300 \mathrm{mmol})$, dodecane (internal standard for GC) and $m$-xylene $(1.2 \mathrm{ml})$ at $120{ }^{\circ} \mathrm{C}$ for 16 h. Analysis of the reaction mixture by GC showed that 2-phenoxy-1-phenylethan-1-one (4\%) formed

Fragmentation of 2-phenoxy-1-phenylethan-1-ol catalyzed by $\mathrm{Ru} / \mathrm{C}$ catalyst (Table 1, Entry 6)

The reaction was conducted according to the General Procedure with $\mathrm{Ru} / \mathrm{C}(5.0 \mathrm{wt} \%$, $\left.60.6 \mathrm{mg}, 3.00 \times 10^{-2} \mathrm{mmol}, 10.0 \mathrm{~mol} \%\right)$, 2-phenoxy-1-phenylethan-1-ol (64.3 mg, 0.300 mmol), dodecane (internal standard for GC) and $m$-xylene $(1.2 \mathrm{ml})$ at $120{ }^{\circ} \mathrm{C}$ for $16 \mathrm{~h}$. Analysis of the reaction mixture by GC showed that phenol (17\%), acetophenone (15\%) and 2-phenoxy-1-phenylethan-1-one (15\%) formed.

Fragmentation of 2-phenoxy-1-phenylethan-1-ol catalyzed by $\mathrm{Ru} / \mathrm{Al}_{2} \mathrm{O}_{3}$ catalyst 


\section{(Table 1, Entry 7)}

The reaction was conducted according to the General Procedure with $\mathrm{Ru} / \mathrm{Al}_{2} \mathrm{O}_{3}(5.0 \mathrm{wt} \%$, $\left.60.6 \mathrm{mg}, 3.00 \times 10^{-2} \mathrm{mmol}, 10.0 \mathrm{~mol} \%\right)$, 2-phenoxy-1-phenylethan-1-ol (64.3 mg, 0.300 mmol), dodecane (internal standard for GC) and $m$-xylene $(1.2 \mathrm{ml})$ at $120{ }^{\circ} \mathrm{C}$ for $16 \mathrm{~h}$. Analysis of the reaction mixture by GC showed that phenol (10\%), acetophenone (10\%) and 2-phenoxy-1-phenylethan-1-one (11\%) formed

Fragmentation of 2-phenoxy-1-phenylethan-1-ol catalyzed by $\mathrm{Rh} / \mathrm{C}$ catalyst (Table 1, Entry 8)

The reaction was conducted according to the General Procedure with $\mathrm{Rh} / \mathrm{C}(5.0 \mathrm{wt} \%$, $\left.61.7 \mathrm{mg}, 3.00 \times 10^{-2} \mathrm{mmol}, 10.0 \mathrm{~mol} \%\right)$, 2-phenoxy-1-phenylethan-1-ol (64.3 mg, 0.300 mmol), dodecane (internal standard for GC) and $m$-xylene $(1.2 \mathrm{ml})$ at $120{ }^{\circ} \mathrm{C}$ for $16 \mathrm{~h}$. Analysis of the reaction mixture by GC showed that phenol (15\%), acetophenone (11\%) and 2-phenoxy-1-phenylethan-1-one (15\%) formed.

Fragmentation of 2-phenoxy-1-phenylethan-1-ol catalyzed by $\mathrm{Pt} / \mathrm{Al}_{2} \mathrm{O}_{3}$ catalyst (Table 1, Entry 9)

The reaction was conducted according to the General Procedure with $\mathrm{Pt} / \mathrm{Al}_{2} \mathrm{O}_{3}(5.0 \mathrm{wt} \%$, $\left.117 \mathrm{mg}, 3.00 \times 10^{-2} \mathrm{mmol}, 10.0 \mathrm{~mol} \%\right)$, 2-phenoxy-1-phenylethan-1-ol (64.3 mg, 0.300 mmol), dodecane (internal standard for GC) and $m$-xylene $(1.2 \mathrm{ml})$ at $120{ }^{\circ} \mathrm{C}$ for $16 \mathrm{~h}$. Analysis of the reaction mixture by GC showed that phenol (63\%), acetophenone (82\%) and 2-phenoxy-1-phenylethan-1-one (8\%) formed.

Fragmentation of 2-phenoxy-1-phenylethan-1-ol catalyzed by Pt/C catalyst (Table 1, Entry 10)

The reaction was conducted according to the General Procedure with $\mathrm{Pt} / \mathrm{C}(10.0 \mathrm{wt} \%$, $58.5 \mathrm{mg}, 3.00 \times 10^{-2} \mathrm{mmol}, 10.0 \mathrm{~mol} \%$ ), 2-phenoxy-1-phenylethan-1-ol (64.3 mg, 0.300 mmol), dodecane (internal standard for GC) and $m$-xylene $(1.2 \mathrm{ml})$ at $120{ }^{\circ} \mathrm{C}$ for $16 \mathrm{~h}$. Analysis of the reaction mixture by GC showed that phenol (44\%), acetophenone (45\%) and 2-phenoxy-1-phenylethan-1-one (12\%) formed.

Fragmentation of 2-phenoxy-1-phenylpropane-1,3-diol catalyzed by $\mathrm{Pd} / \mathrm{C}$ catalyst (Eq 1) 
The reaction was conducted according to the General Procedure with $\mathrm{Pd} / \mathrm{C}(10.0 \mathrm{wt} \%$, $\left.16.0 \mathrm{mg}, 1.50 \times 10^{-2} \mathrm{mmol}, 5.0 \mathrm{~mol} \%\right)$, 2-phenoxy-1-phenylpropane-1,3-diol (73.3 mg, $0.300 \mathrm{mmol}$ ), dodecane (internal standard for $\mathrm{GC}$ ) and $p$-cymene/dioxane (1:1 mixture, $1.2 \mathrm{ml}$ ) at $200{ }^{\circ} \mathrm{C}$ for $24 \mathrm{~h}$. Analysis of the reaction mixture by $\mathrm{GC}$ showed that ethylbenzene (7\%), phenol (88\%), acetophenone $(70 \%)$ and propiophenone (18\%) formed.

Fragmentation of 1-(3,4-dimethoxyphenyl)-2-(2-methoxyphenoxy)propane-1,3-diol catalyzed by $\mathrm{Pd} / \mathrm{C}$ catalyst (Eq 2)

The reaction was conducted according to the General Procedure with $\mathrm{Pd} / \mathrm{C}(10.0 \mathrm{wt} \%$, $\left.16.0 \mathrm{mg}, \quad 1.50 \times 10^{-2} \mathrm{mmol}, \quad 5.0 \quad \mathrm{~mol} \%\right)$, 1-(3,4-dimethoxyphenyl)-2-(2methoxyphenoxy)propane-1,3-diol $(100 \mathrm{mg}, 0.300 \mathrm{mmol})$, dodecane (internal standard for GC) and $p$-cymene/dioxane (1:1 mixture, $1.2 \mathrm{ml})$ at $200{ }^{\circ} \mathrm{C}$ for $24 \mathrm{~h}$. Analysis of the reaction mixture by GC showed that 1,2-dimethoxy-4-ethylbenzene (65\%), guaiacol (90\%), 1,2-dimethoxy-4-propylbenzene (trace) and small quantity of unidentified higher molecular weight products formed.

Fragmentation of 1-(4-hydroxy-3-methoxyphenyl)-2-(2-methoxyphenoxy)propane1,3-diol catalyzed by $\mathrm{Pd} / \mathrm{C}$ catalyst ( $\mathrm{Eq} 3)$

The reaction was conducted according to the General Procedure with $\mathrm{Pd} / \mathrm{C}(10.0 \mathrm{wt} \%$, $\left.16.0 \mathrm{mg}, \quad 1.50 \times 10^{-2} \mathrm{mmol}, \quad 5.0 \mathrm{~mol} \%\right), \quad$ 1-(4-hydroxy-3-methoxyphenyl)-2-(2methoxyphenoxy)propane-1,3-diol $(96.1 \mathrm{mg}, 0.300 \mathrm{mmol}$ ), dodecane (internal standard for GC) in a combination of $p$-cymene and dioxane $(1: 1$ mixture, $1.2 \mathrm{ml})$ at $200{ }^{\circ} \mathrm{C}$ for 24 h. Analysis of the reaction mixture by GC showed that 4-ethylguaiacol (45\%), guaiacol (67\%), 4-(3-hydroxy-2-(2-methoxyphenoxy)propyl)-2-methoxyphenol (15\%) and small quantity of unidentified higher molecular weight products formed.

Competition experiment: fragmentation of a 1:1 mixture of 2-phenoxy-1phenylethan-1-ol and 2-(2-methoxyphenoxy)-1-phenylethan-1-one catalyzed by $\mathrm{Pd} / \mathrm{C}$ catalyst (Eq 4)

The reaction was conducted according to the General Procedure with $\mathrm{Pd} / \mathrm{C}(10.0 \mathrm{wt} \%$, 
$\left.16.0 \mathrm{mg}, 1.50 \times 10^{-2} \mathrm{mmol}, 5.0 \mathrm{~mol} \%\right)$, 2-phenoxy-1-phenylethan-1-ol (32.1 mg, 0.150 mmol), 2-(2-methoxyphenoxy)-1-phenylethan-1-one (36.3 mg, $0.150 \mathrm{mmol})$, dodecane (internal standard for GC) and $m$-xylene $(1.2 \mathrm{ml})$ at $120{ }^{\circ} \mathrm{C}$ for $4 \mathrm{~h}$. Analysis of the reaction mixture by GC showed that guaiacol (92\%), phenol (6\%), acetophenone (103\%), 2-(2-methoxyphenoxy)-1-phenylethan-1-ol (5\%) and 2-phenoxy-1-phenylethan-1-one (88\%) formed at $94 \%$ conversion of 2-(2-methoxyphenoxy)-1-phenylethan-1-one and $98 \%$ conversion of 2-phenoxy-1-phenylethan-1-ol.

\section{Time profile analysis: fragmentation of 2-phenoxy-1-phenylpropane-1,3-diol catalyzed by Pd/C catalyst (Figure 1)}

The reaction was conducted according to the General Procedure with $\mathrm{Pd} / \mathrm{C}(10.0 \mathrm{wt} \%$, $\left.16.0 \mathrm{mg}, 1.50 \times 10^{-2} \mathrm{mmol}, 5.0 \mathrm{~mol} \%\right)$, 2-phenoxy-1-phenylpropane-1,3-diol (73.2 mg, $0.300 \mathrm{mmol})$, dodecane (internal standard for $\mathrm{GC}$ ) and $p$-cymene/dioxane (1:1 mixture, $1.2 \mathrm{ml})$ at $200{ }^{\circ} \mathrm{C}$ for $8 \mathrm{~h}$. Small aliquots of the reaction mixture were removed after 5 min, $15 \mathrm{~min}, 30 \mathrm{~min}, 1 \mathrm{~h}, 2 \mathrm{~h}, 4 \mathrm{~h}, 6 \mathrm{~h}, 8 \mathrm{~h}$, and the samples were analyzed by GC. The amount of identified products was plotted against time to reveal the progress of this fragmentation reaction within the first $8 \mathrm{~h}$ of the reaction time. For the detailed discussion, please see the main text.

\section{HSQC spectra of the aromatic regions of isolated lignin samples from M. Giganteus through organosolvolysis (with ethanol, acetone and dixoane).}

The full analysis of these lignin samples through 2D NMR was disclosed previously. ${ }^{10}$ 


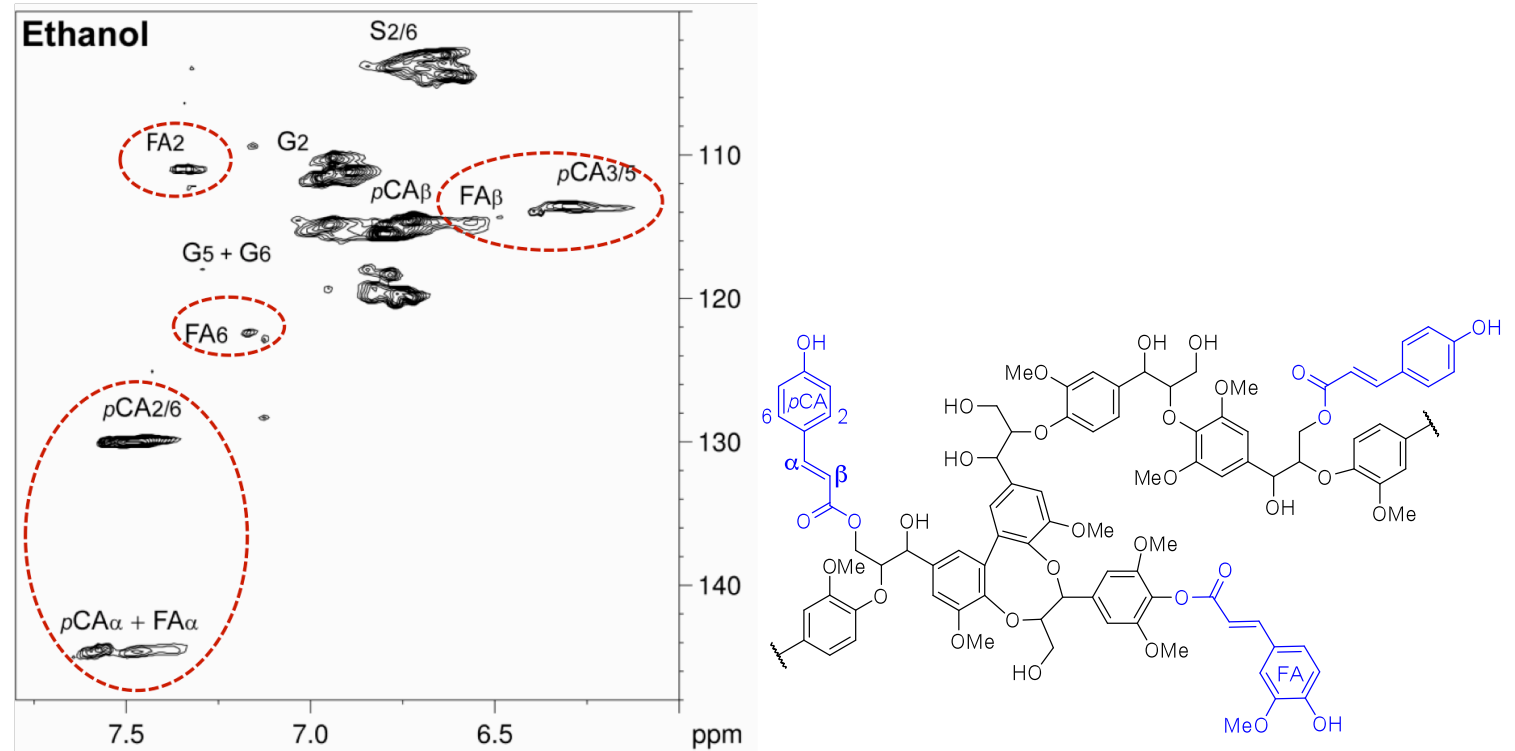

P-hydroxycinnamates units (P-CA and FA) in Ethanol-solv Miscanthus G. lignin
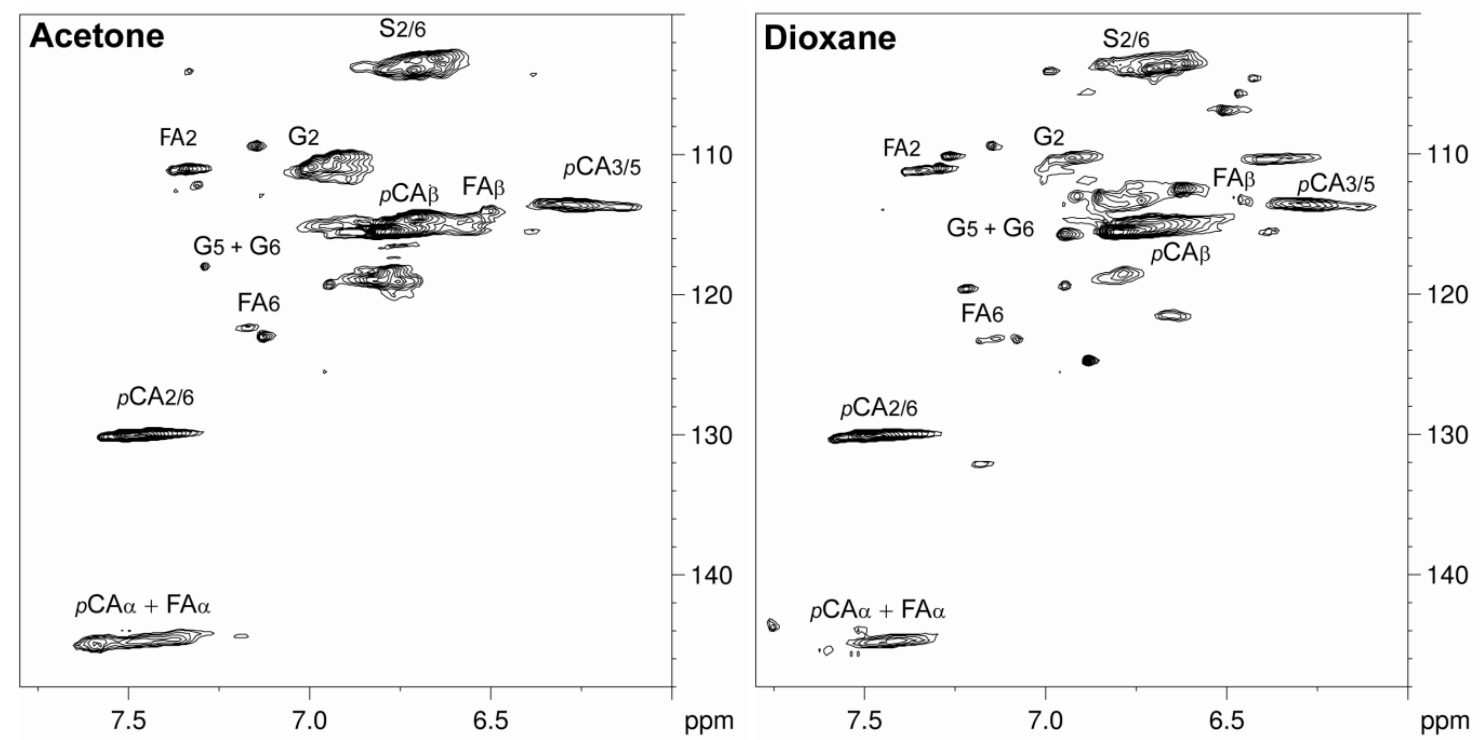

P-CA and FA units in Acetone \& Dioxane-solv M. Giganteus lignin

Figure S1. HSQC spectra of the aromatic regions of lignin samples isolated from $M$. Giganteus through ethanol-, acetone-, and dixoane-solvolysis

The procedure for $\mathrm{Pd} / \mathrm{C}$ catalyzed fragmentation of the isolated acetone-solv lignin sample from M. Giganteus under hydrogen free conditions

In a glovebox, a $15 \mathrm{ml}$ glass tube $(\sim 10 \mathrm{~cm}$ long $\mathrm{X} 1.0 \mathrm{~cm}$ in diameter $)$ equipped with a 
Teflon-coated magnetic stir bar was charged with $\mathrm{Pd} / \mathrm{C}\left(10.0 \mathrm{wt} \%, 63.9 \mathrm{mg}, 6.00 \times 10^{-2}\right.$ $\mathrm{mmol}, 20.0 \mathrm{~mol} \%)$, the acetonesolv lignin $(59.4 \mathrm{mg}, 0.300 \mathrm{mmol})$ and a magnetic stir bar. Then, $1.2 \mathrm{~mL}$ dioxane was added, and the mixture was stirred for $5 \mathrm{~min}$ to dissolve the lignin sample. The tube was sealed with the Teflon-lined screw cap and removed from the glovebox. The vessel was heated in an oil bath at $200{ }^{\circ} \mathrm{C}$ for $24 \mathrm{~h}$. The resulting dark black mixture was cooled to room temperature, diluted with additional amount of dioxane $(1 \mathrm{ml})$, and passed through a short plug of Celite $(2 \mathrm{~cm}$ in length) to remove black solid materials. Additional portions of dioxane $(3 \times 1.0 \mathrm{~mL})$ were used to wash the Celite, and the filtrates were combined to give a brown clear solution. Volatile materials were evaporated under vacuum, and the resulting dark black residual was subjected to high vacuum ( $<50$ torr) for at least $24 \mathrm{~h}$ to remove remaining volatile compounds to generate a dark brown oily film (55.7 mg, 94\% yield of recovery). The dark brown material was characterized by HSQC experiment.

A control experiment was conducted exactly as described above except for the exclusion of the $\mathrm{Pd} / \mathrm{C}$ catalyst in the reaction. A dark brown solid was obtained $(57.6 \mathrm{mg}, 97 \%$ yield of recovery) and analyzed by HSQC experiment. The data were used for comparison purposes. 

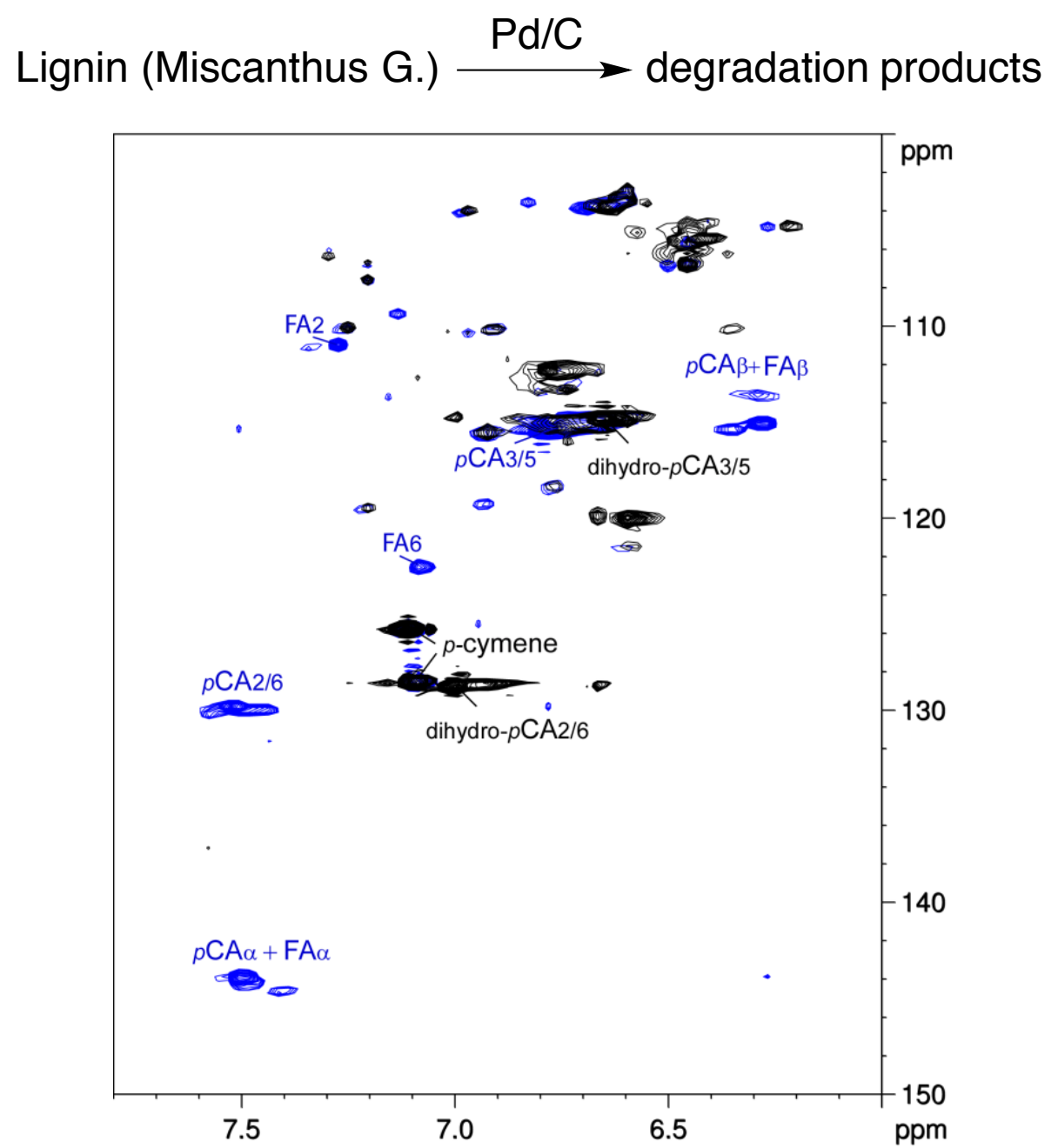

Double bonds disappeared after treatment with $\mathrm{Pd} / \mathrm{C}$ without added $\mathrm{H}_{2}$

Figure S2. HSQC spectrum of the degradation product of acetone-solv lignin with $\mathrm{Pd} / \mathrm{C}$ without added $\mathrm{H}_{2}$ in comparison to the acetone-solv lignin from M. Giganteus (aromatic region)

The procedure for hydrogenative treatment of dioxanesolv lignin samples from $M$. Giganteus

In a glovebox, a $50 \mathrm{~mL}$ round bottom flask equipped with a stir bar was charged with 10 wt \% Pd/C (106 mg, $0.100 \mathrm{mmol}, 1.0 \mathrm{~mol} \%$ ) and dioxanesolv lignin (1.98 g, 10.0 mmol). The flask was sealed with a septum and removed from the glovebox. The vessel was attached to a manifold, and the reaction atmosphere was switched to hydrogen by 
three vacuum $/ \mathrm{H}_{2}$ refill cycles. After that, dioxane $(20.0 \mathrm{~mL})$ was introduced via a syringe. The reaction mixture was allowed to stir under one atmosphere of hydrogen (with a $\mathrm{H}_{2}$ balloon) at $22{ }^{\circ} \mathrm{C}$ for $4 \mathrm{~h}$. The black suspension was then exposed to air and passed through a plug of Celite, and the Celite containing the residue was eluted with additional dioxane $(3 \times 10.0 \mathrm{~mL})$. Low boiling solvents in the combined organic filtrate were evaporated under vacuum. The residue was further subjected to high vacuum ( $<50$ torr) for at least $24 \mathrm{~h}$, resulting in a dark brown solid (1.93 g, 97\% yield of recovery). The material was characterized by HSQC and GPC experiments, and used in the following fragmentation study.

\section{The procedure for $\mathrm{Pd} / \mathrm{C}$ catalyzed fragmentation of the reduced acetonesolv lignin sample under hydrogen free conditions (Scheme 3)}

In a glovebox, a $15 \mathrm{ml}$ glass tube $(\sim 10 \mathrm{~cm}$ long $\mathrm{X} 1.0 \mathrm{~cm}$ in diameter) equipped with a Teflon-coated magnetic stir bar was charged with $\mathrm{Pd} / \mathrm{C}\left(10.0 \mathrm{wt} \%, 63.9 \mathrm{mg}, 6.00 \times 10^{-2}\right.$ $\mathrm{mmol}, 20.0 \mathrm{~mol} \%$ ), the acetonesolv lignin pretreated with hydrogen as described in the previous procedure $(59.4 \mathrm{mg}, 0.300 \mathrm{mmol})$ and a magnetic stir bar. Then, $1.2 \mathrm{~mL}$ dioxane was added, and the mixture was stirred for $5 \mathrm{~min}$ to dissolve the lignin sample. The tube was sealed with the Teflon-lined screw cap and removed from the glovebox. The vessel was heated in an oil bath at $200{ }^{\circ} \mathrm{C}$ for $24 \mathrm{~h}$. The resulting dark black mixture was cooled to room temperature, diluted with additional amount of dioxane $(1 \mathrm{ml})$, and passed through a short plug of Celite $(2 \mathrm{~cm}$ in length) to remove black solid materials. Additional portions of dioxane $(3 \times 1.0 \mathrm{~mL})$ were used to wash the Celite, and the filtrates were combined to give a brown clear solution. Volatile materials were evaporated under vacuum, and the resulting dark black residual was subjected to high vacuum ( $<50$ torr) for at least $24 \mathrm{~h}$ to remove remaining volatile compounds to generate a dark brown oily film (50.5 $\mathrm{mg}, 85 \%$ yield of recovery). The dark brown material was characterized by HSQC and GPC experiments.

A control experiment was conducted exactly as described above except for the exclusion of the $\mathrm{Pd} / \mathrm{C}$ catalyst in the reaction. A dark brown solid was obtained $(58.4 \mathrm{mg}, 98 \%$ yield of recovery) and analyzed by HSQC and GPC experiments. The data were used for 
comparison purposes (cf. Scheme 3 in the main text).
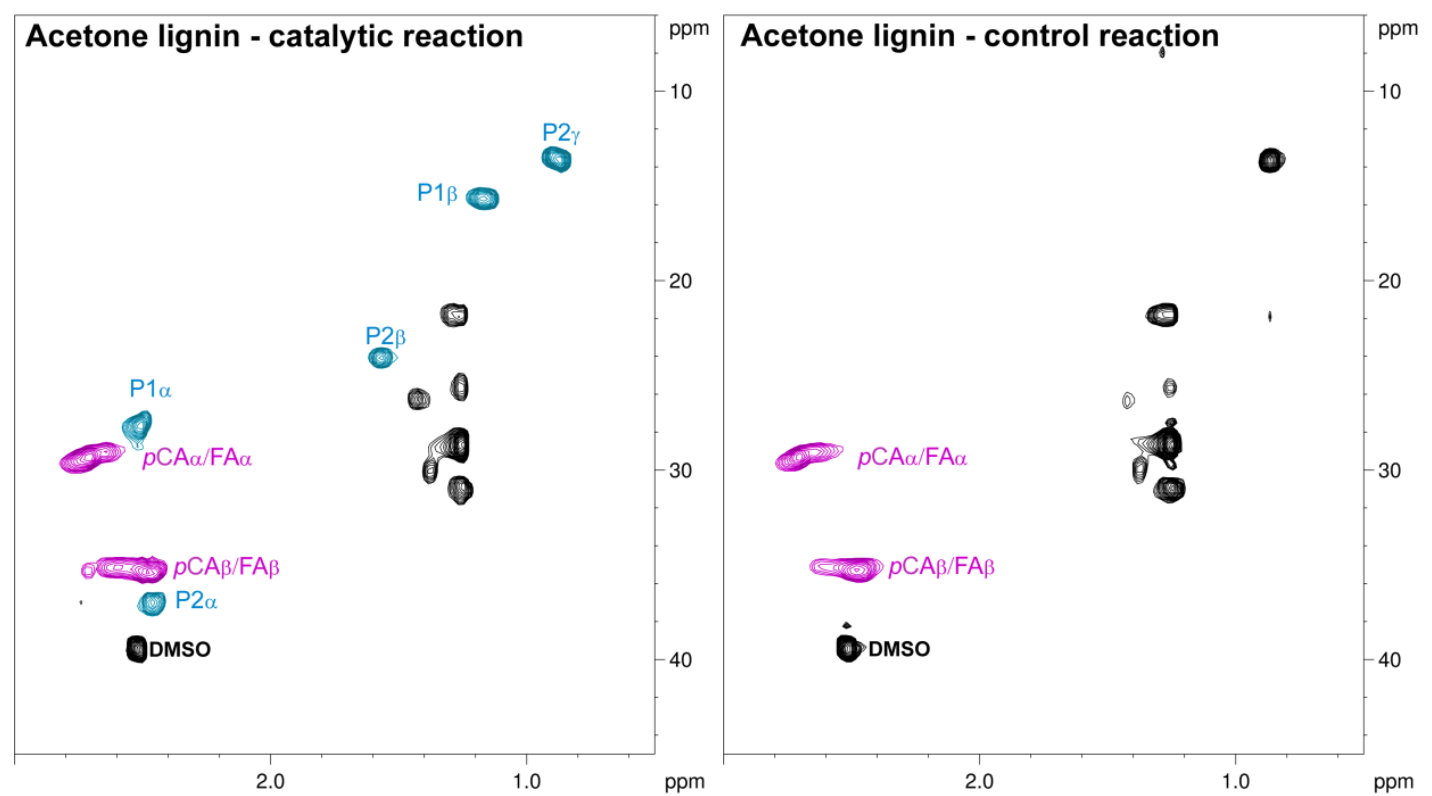

Signals for alkyl chains in the aliphatic region resulting from lignin degradation catalyzed by $\mathrm{Pd} / \mathrm{C}$

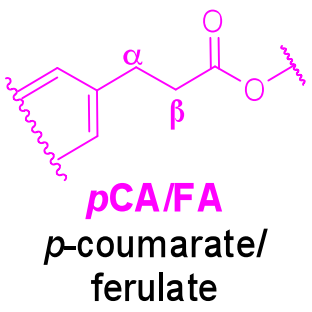

P1

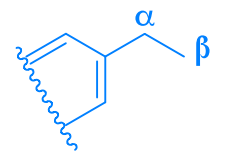

P2

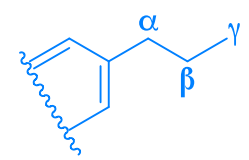

Figure S3. HSQC spectra of the degraded material and the starting hydrogenatively treated acetonesolv lignin (aliphatic region)

General procedure for the $\mathrm{Pd} / \mathrm{C}$ catalyzed fragmentation of lignin samples under 1 atm of hydrogen 
Reactions were conducted in $15 \mathrm{ml}$ glass Schlenk vessels (made from glass tubes with an outer diameter of $16 \mathrm{~mm}$; the volume of the vessels is 13.1-14.8 ml) equipped with Teflon screw valves and Teflon-coated magnetic stir bars $(3 \mathrm{~mm} \times 10 \mathrm{~mm}$; supplied by Fisher Scientific). The reported pressure of hydrogen was measured at room temperature, and the pressure refers to the reading from the gauge of the gas cylinder. The reaction vessels were heated in an oil bath; the reaction temperature refers to the temperature of the oil bath. The stirring rate was kept constant at $900 \mathrm{rpm}$ (Magnetic stirrer IKA Ceramag Midi; the stir rate dial was set to 7.5).

In a glovebox, a $15 \mathrm{ml}$ Schlenk vessel equipped with a Teflon screw valve was charged with $10 \mathrm{wt} \% \mathrm{Pd} / \mathrm{C}\left(63.9 \mathrm{mg}, 6.00 \times 10^{-2} \mathrm{mmol}\right.$ of pure palladium, $\left.20.0 \mathrm{~mol} \%\right)$, a lignin sample $(\sim 60.0 \mathrm{mg}, 0.300 \mathrm{mmol})$ and a magnetic stir bar. Then, dioxane $(1.2 \mathrm{ml})$ was added, and the mixture was stirred for 5 min to dissolve the lignin. The Schlenk vessel was sealed with the Teflon screw valve and removed from the glovebox. The reaction mixture was degassed via two cycles of freeze-pump-thaw, and the vessel was pressurized with 1 bar (15 psi) of hydrogen at room temperature. The vessel was sealed with the Teflon valve and heated in an oil bath at $200^{\circ} \mathrm{C}$ for $24 \mathrm{~h}$. The resulting dark black mixture was cooled to room temperature, diluted with additional dioxane $(1.0 \mathrm{ml})$, and passed through a short plug of Celite $(2 \mathrm{~cm}$ in length) to remove black solid materials. Additional portions of dioxane $(3 \times 1.0 \mathrm{~mL})$ were used to wash the Celite, and the filtrates were combined to give a clear dark brown solution. A small aliquot $(100 \mu \mathrm{L})$ of the resulting solution was removed and subjected to treatment with excess N,Obis(trimethylsilyl)trifluoroacetamide (10 equivalents vs. substrate) at $65{ }^{\circ} \mathrm{C}$ for one hour. The silylation of phenols and alcohols give products with narrow peaks in the GC and GC-MS traces for these mono-lignols, as reported previously. ${ }^{10}$ The products have all been reported previously and were identified by comparison of the mass spectra and retention times of the products by GC/MS and GC with those of authentic compounds obtained commercially or synthesized. The volatile materials were evaporated under vacuum, and the resulting dark black residue was subjected to high vacuum ( $<50$ torr) for at least $24 \mathrm{~h}$ to remove remaining volatile compounds. This procedure generated a dark brown oily film (67-79\% yield of recovery). The dark brown material was further characterized by HSQC and GPC experiments. 
The procedure for $\mathrm{Pd} / \mathrm{C}$ catalyzed fragmentation of the synthetic lignin under an atmospheric pressure of hydrogen (Scheme 4)

The reaction was conducted according to the general procedure with $\mathrm{Pd} / \mathrm{C}(63.9 \mathrm{mg}$, $\left.6.00 \times 10^{-2} \mathrm{mmol}, 20.0 \mathrm{~mol} \%\right)$, synthetic lignin (59.4 mg, $\left.0.300 \mathrm{mmol}\right)$, dioxane (1.2 ml) and $\mathrm{H}_{2}(15 \mathrm{psi})$ at $200{ }^{\circ} \mathrm{C}$ for $24 \mathrm{~h}$. The resulting dark brown oily film $(31.4 \mathrm{mg}, 53 \%$ yield of recovery) was analyzed by HSQC and GPC.

A control experiment was conducted exactly as described above except for the exclusion of the $\mathrm{Pd} / \mathrm{C}$ catalyst in the reaction. A dark brown solid was obtained $(57.7 \mathrm{mg}, 97 \%$ yield of recovery). This solid was analyzed by HSQC and GPC experiments, and the data were used for comparison purposes (cf. Scheme 4 in the main text).

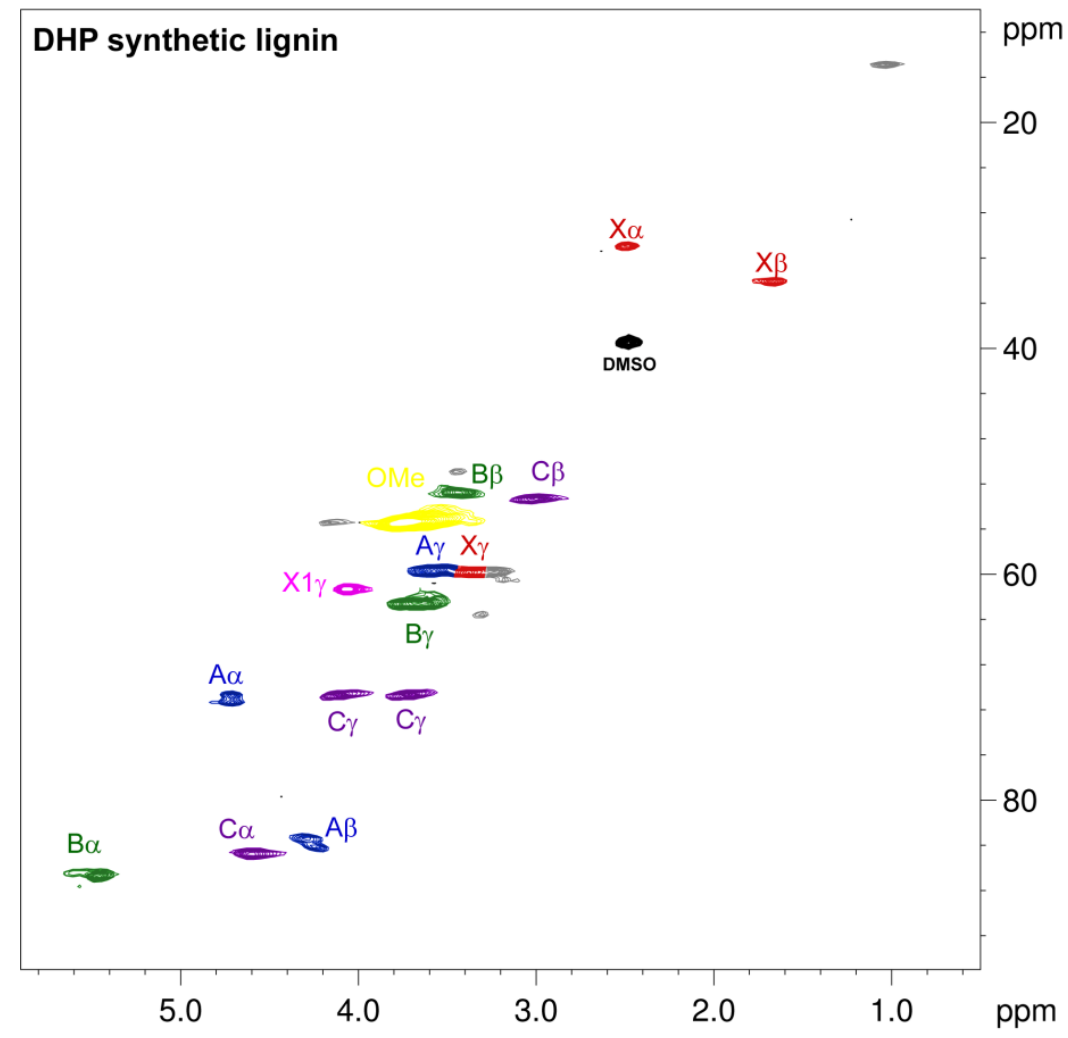

Major linkages identified from synthetic lignin sample 


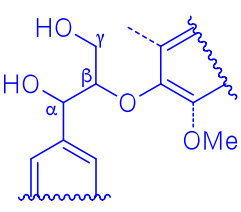

A $\beta$-aryl ether

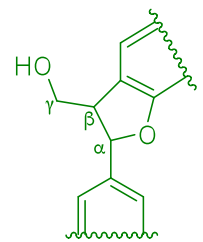

B

phenylcoumaran

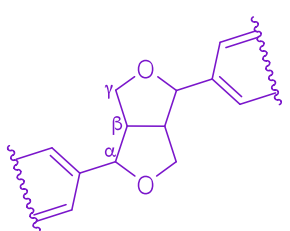

C resinol methoxyl

unassigned

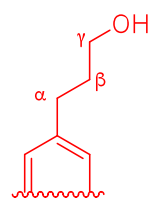

$X$

hydrocinnamyl alcohol

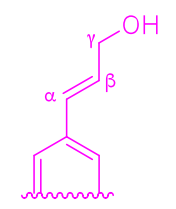

$X_{1}$

coniferyl alcohol

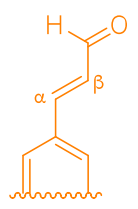

$X_{2}$

coniferyl aldehyde

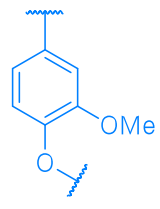

G

guaiacyl

Figure S4. HSQC spectrum of the synthetic lignin and linkage analysis

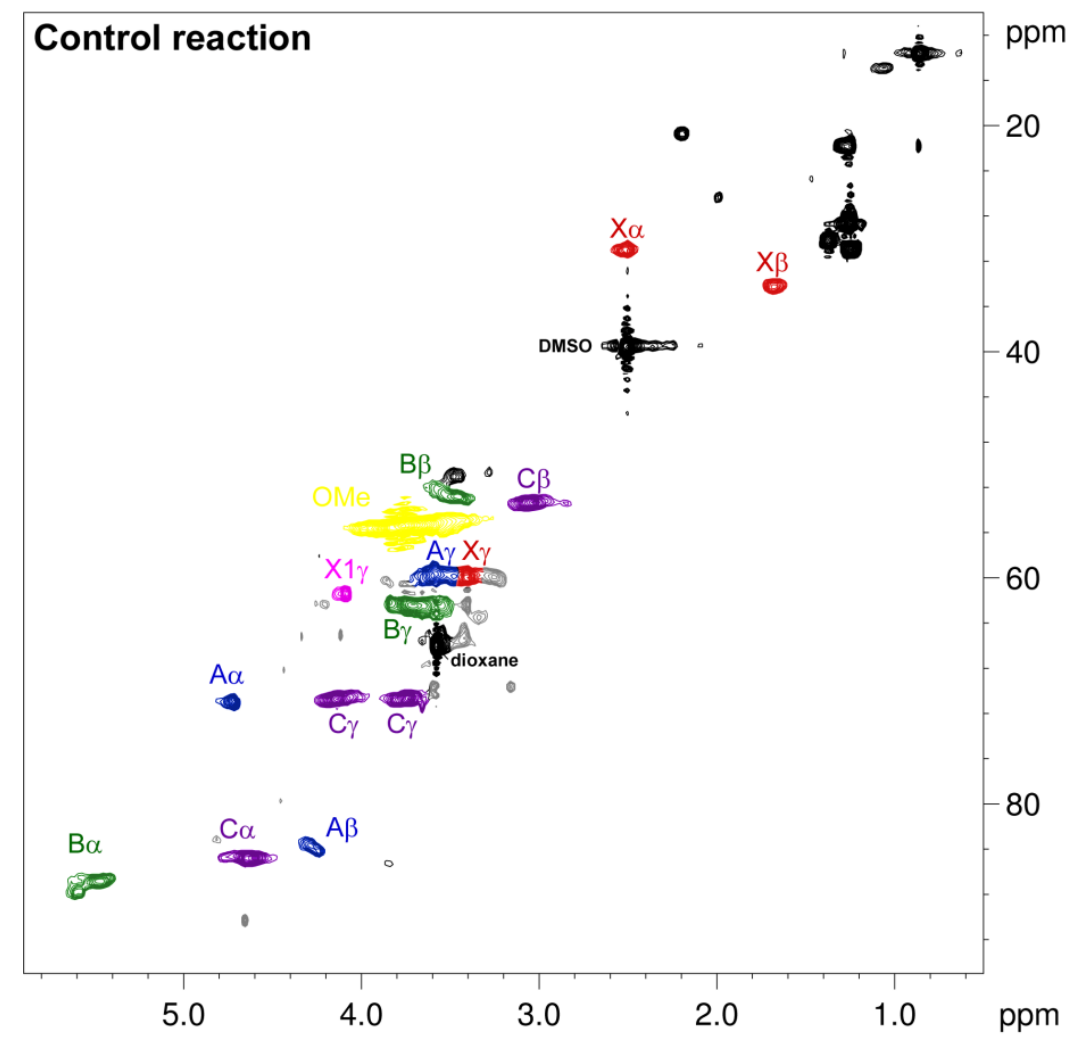




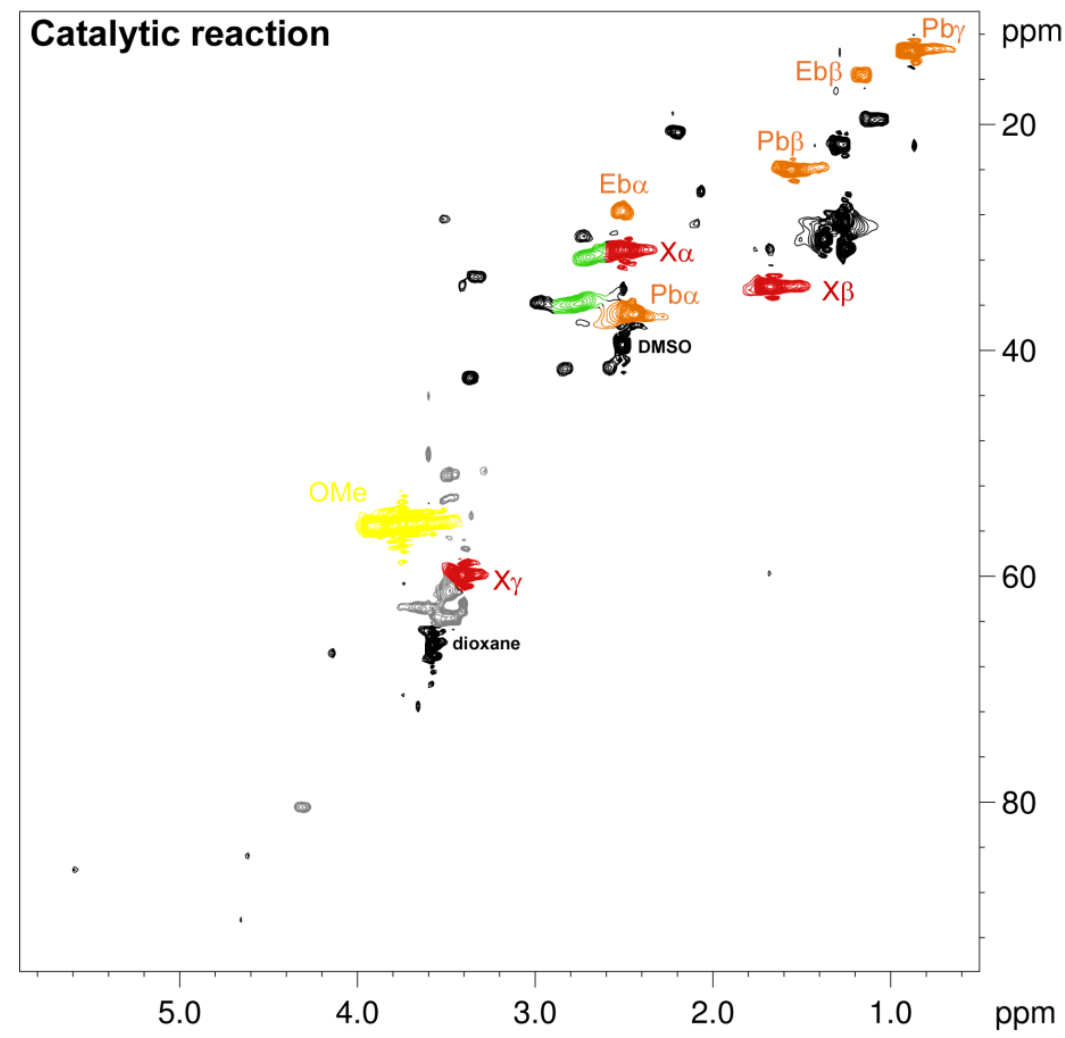

Major aliphatic products formed:

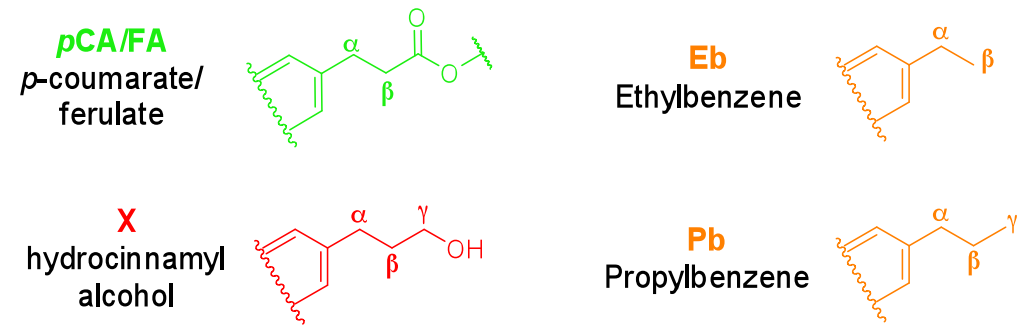

Figure S5. HSQC spectra of the degraded material after fragmentation and of the material obtained from the control experiment (aliphatic and oxygenated region) 


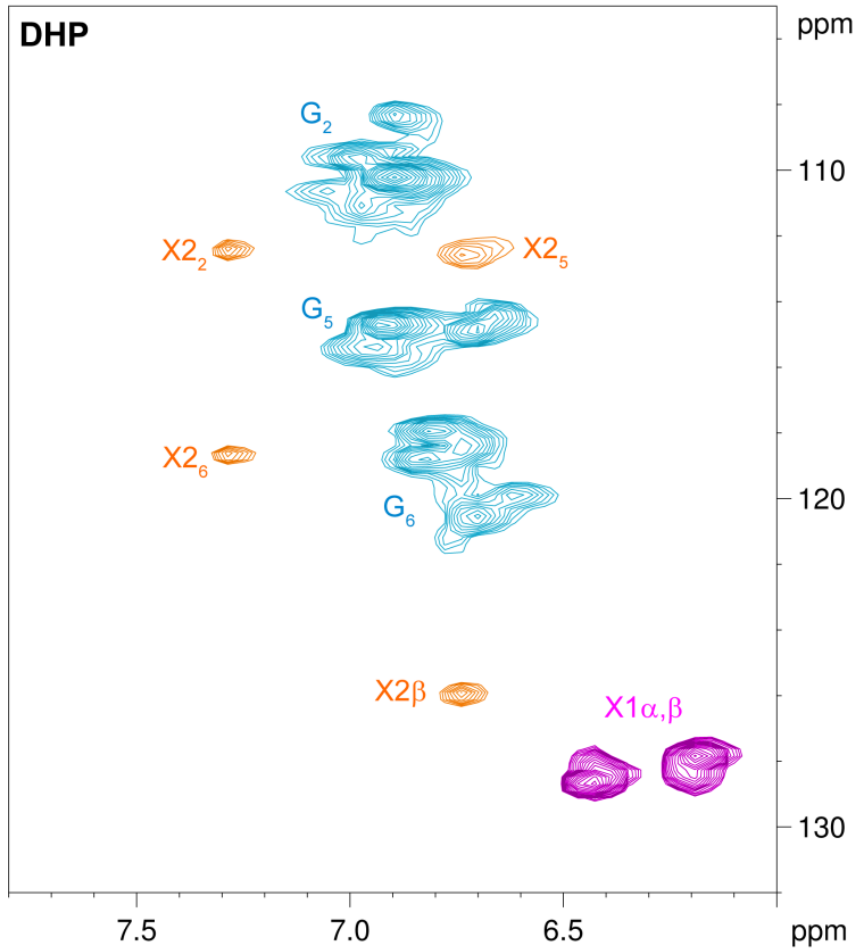

Peak assignment for the aromatic region:
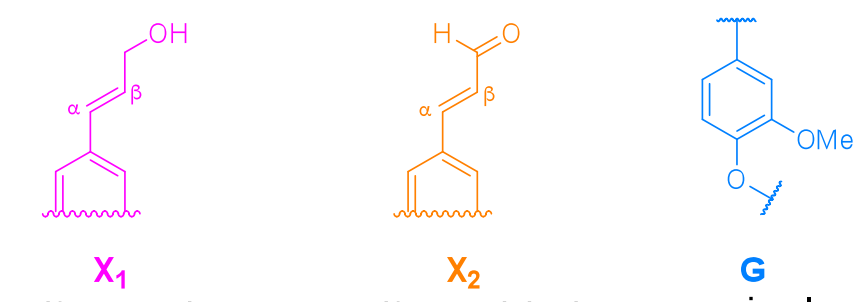

coniferyl alcohol

coniferyl aldehyde

G

guaiacyl 


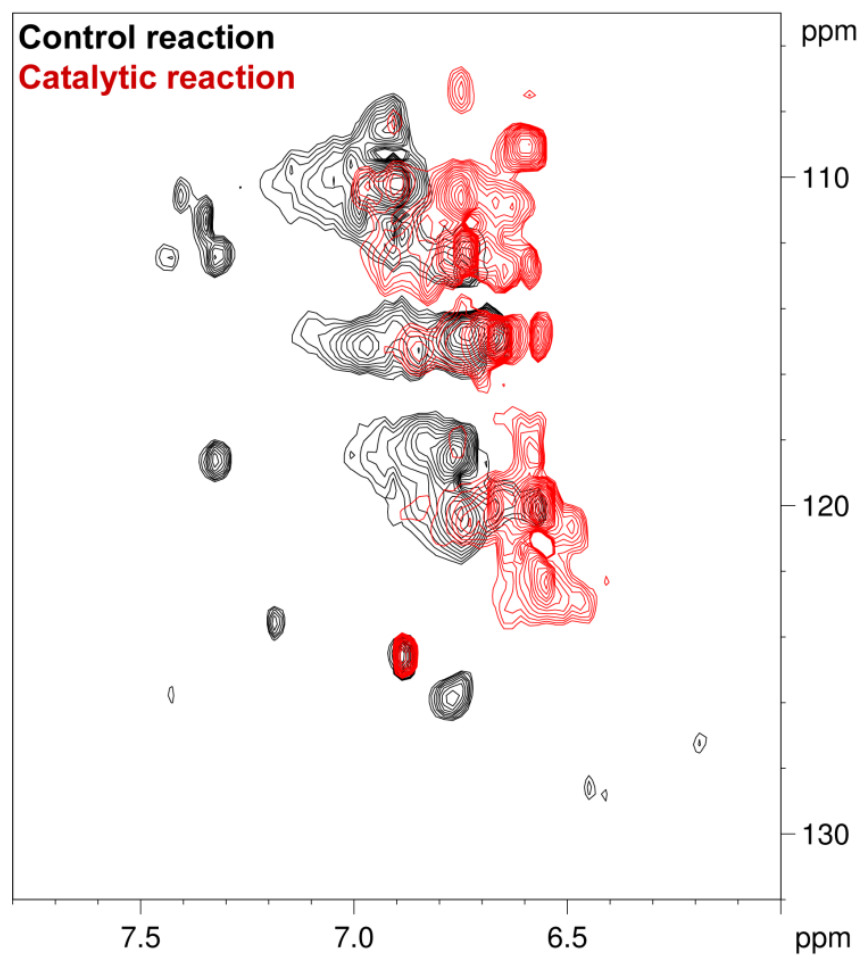

In the catalytic reaction, the aromatic protons resonate at higher field, corresponding to the reduction of the double bonds revealed in the previous graph

Figure S6. HSQC spectra of the degraded material and of the material obtained from the control experiment (aromatic region)

The procedure for $\mathrm{Pd} / \mathrm{C}$ catalyzed fragmentation of acetonesolv lignin under an atmospheric pressure of hydrogen (Figure 2 and Entry 1, Table 2)

The reaction was conducted according to the general procedure with $\mathrm{Pd} / \mathrm{C}(63.9 \mathrm{mg}$, $6.00 \times 10^{-2} \mathrm{mmol}, 20.0 \mathrm{~mol} \%$ ), acetonesolv lignin (59.4 mg, $\left.0.300 \mathrm{mmol}\right)$, dioxane $(1.2 \mathrm{ml})$ and $\mathrm{H}_{2}(15 \mathrm{psi})$ at $200{ }^{\circ} \mathrm{C}$ for $24 \mathrm{~h}$. The resulting dark brown oily film $(39.8 \mathrm{mg}, 67 \%$ yield of recovery) was analyzed by HSQC and GPC. GC analysis of the aliquot obtained from the reaction mixture showed that 4-ethylphenol $19(0.65 \mathrm{mg})$, 4-ethylguaiacol 14 (2.21 mg), 2-methoxy-4-propylphenol 21 (1.19 mg), 4-ethyl-2,6-dimethoxyphenol 20 (2.58 mg), 2,6-dimethoxy-4-propylphenol 22 (1.39 $\mathrm{mg})$, dihydroconiferyl alcohol 23 (0.44 mg), and 4-(3-hydroxypropyl)-2,6-dimethoxyphenol $24(0.51 \mathrm{mg})$ formed in a combined yield of $15.1 \mathrm{wt} \%$. 
A control experiment was conducted exactly as described above except for the exclusion of the $\mathrm{Pd} / \mathrm{C}$ catalyst in the reaction. A dark brown solid was obtained $(55.5 \mathrm{mg}, 93 \%$ yield of recovery). This solid was analyzed by HSQC and GPC, and the data were used for comparison purposes (cf. Figure 2 in the main text).

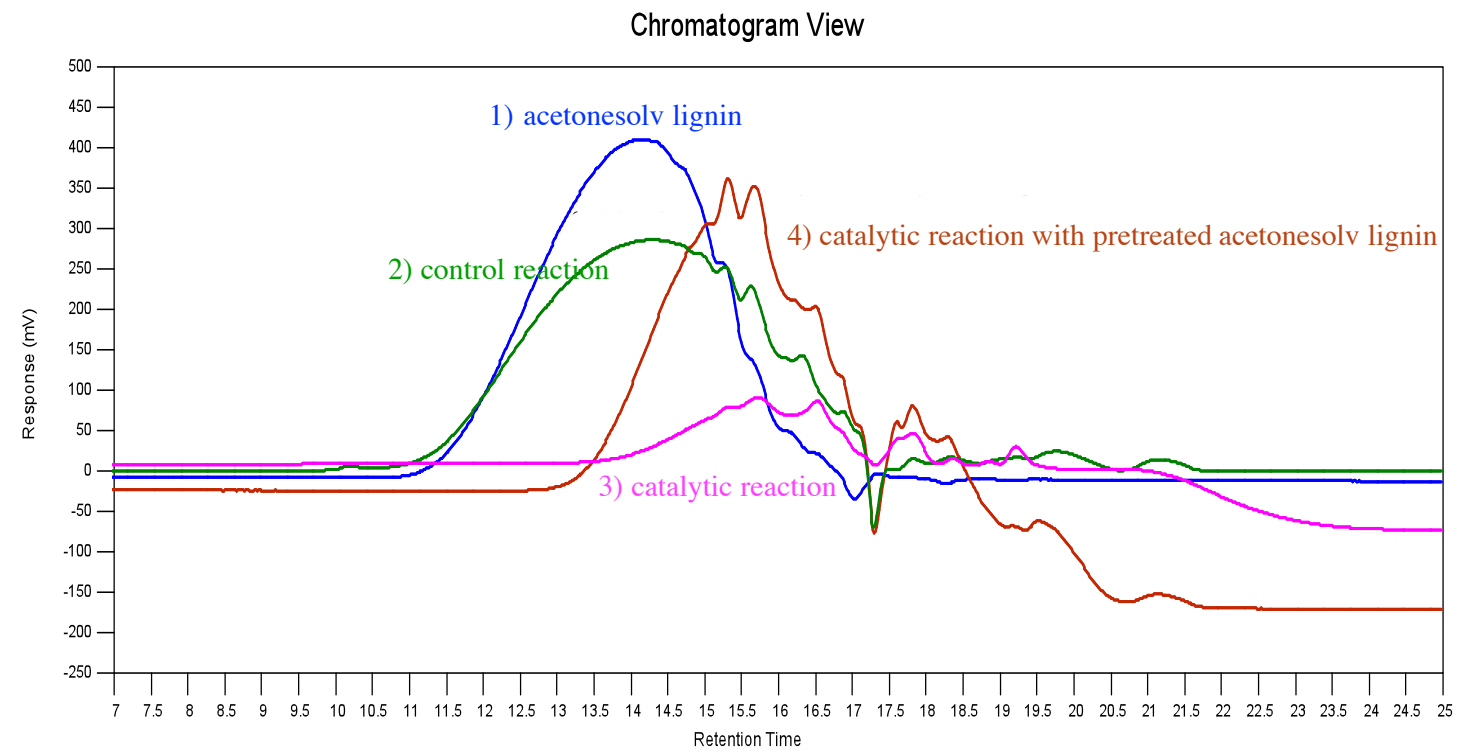

Figure S7. GPC graphs of 1) acetonesolv lignin, 2) material obtained from the control experiment, 3) degraded acetonesolv lignin after fragmentation and 4) overlay with degraded material from the fragmentation of hydrogenatively treated acetonesolv lignin under the hydrogen free condition. 
Table S1. Screening of the BASF heterogeneous catalyst kit for fragmentation of acetonesolv lignin under 15 psi of $\mathrm{H}_{2}$

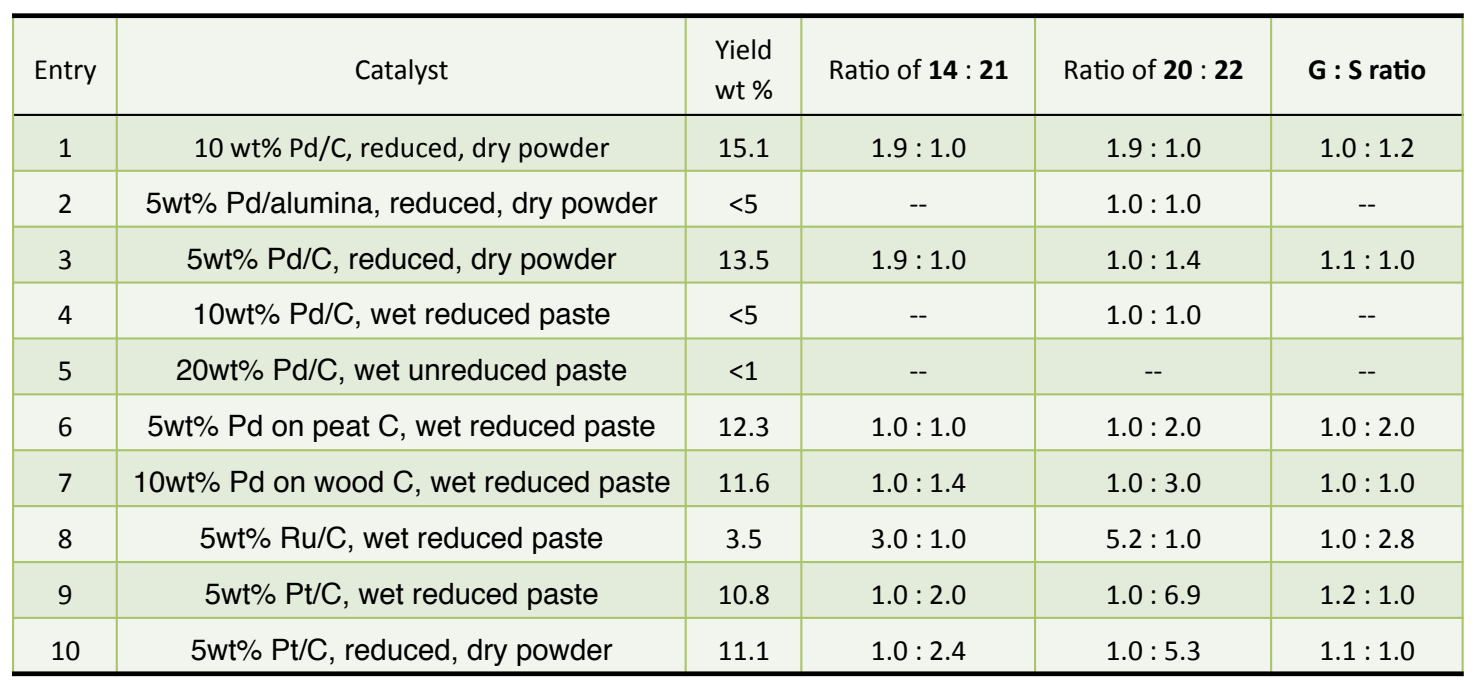

The procedure for fragmentation of ethanolsolv lignin catalyzed by $\mathrm{Pd} / \mathrm{C}$ under an atmospheric pressure of hydrogen (Figure 2 and Entry 2, Table 2)

The reaction was conducted according to the general procedure with $\mathrm{Pd} / \mathrm{C}(63.9 \mathrm{mg}$, $\left.6.00 \times 10^{-2} \mathrm{mmol}, 20.0 \mathrm{~mol} \%\right)$, ethanolsolv lignin ( $\left.59.4 \mathrm{mg}, 0.300 \mathrm{mmol}\right)$, dioxane (1.2 ml) and $\mathrm{H}_{2}(15 \mathrm{psi})$ at $200{ }^{\circ} \mathrm{C}$ for $24 \mathrm{~h}$. The resulting dark brown oily film (43.6 mg, $73 \%$ yield of recovery) was analyzed by HSQC and GPC experiments. GC analysis of the aliquot obtained from the reaction mixture showed that 4-ethylphenol $19(0.57 \mathrm{mg}), 4$ ethylguaiacol 14 (2.13 mg), 2-methoxy-4-propylphenol 21 (0.51 mg), 4-ethyl-2,6dimethoxyphenol 20 (2.61 mg), 2,6-dimethoxy-4-propylphenol $22 \quad(0.63 \quad \mathrm{mg})$, dihydroconiferyl alcohol $\mathbf{2 3}$ (0.33 mg), and 4-(3-hydroxypropyl)-2,6-dimethoxyphenol $\mathbf{2 4}$ $(0.38 \mathrm{mg})$ formed in combined yield of $12.0 \mathrm{wt} \%$.

A control experiment was conducted exactly as described above, except for the exclusion of $\mathrm{Pd} / \mathrm{C}$ catalyst in the reaction. A dark brown solid was obtained $(58.2 \mathrm{mg}, 98 \%$ yield of recovery). The solid was analyzed by HSQC and GPC, and the data were used for comparison purposes (cf. Figure 2 in the main text). 

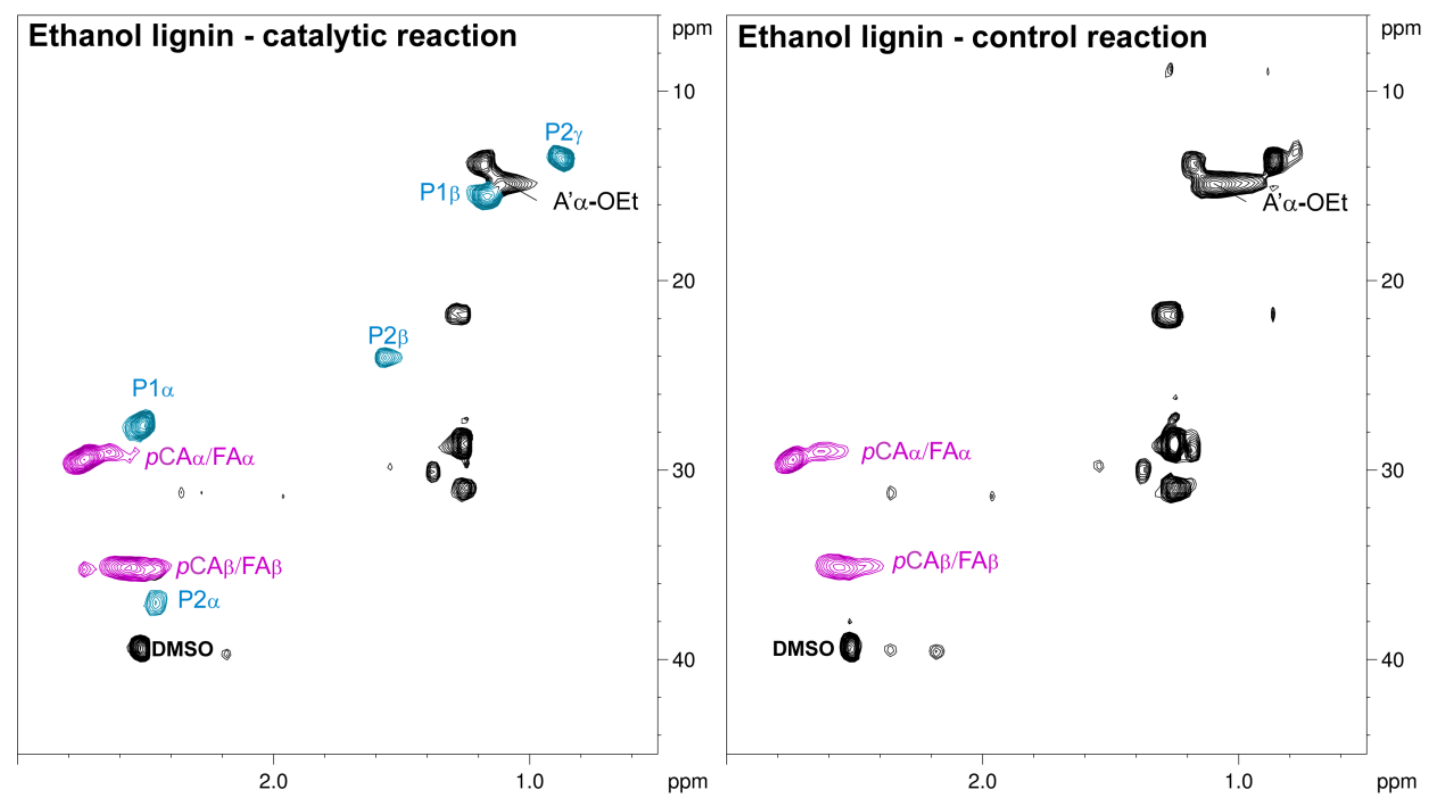

New formation of alkyl chains in the aliphatic region
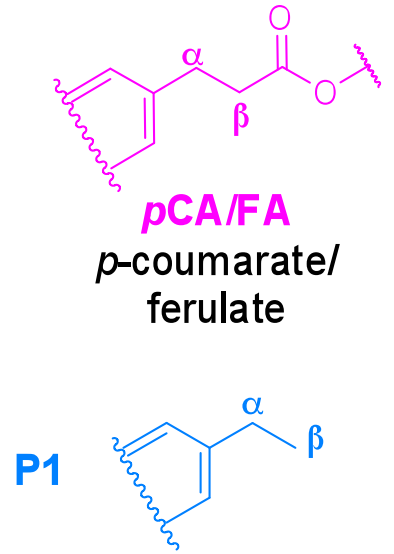

P2

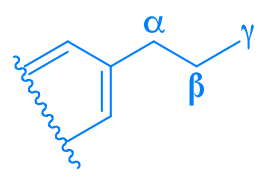

Figure S8. HSQC spectra of the degraded ethanolsolv lignin after fragmentation and of the material obtained from the control experiment (aliphatic region) 


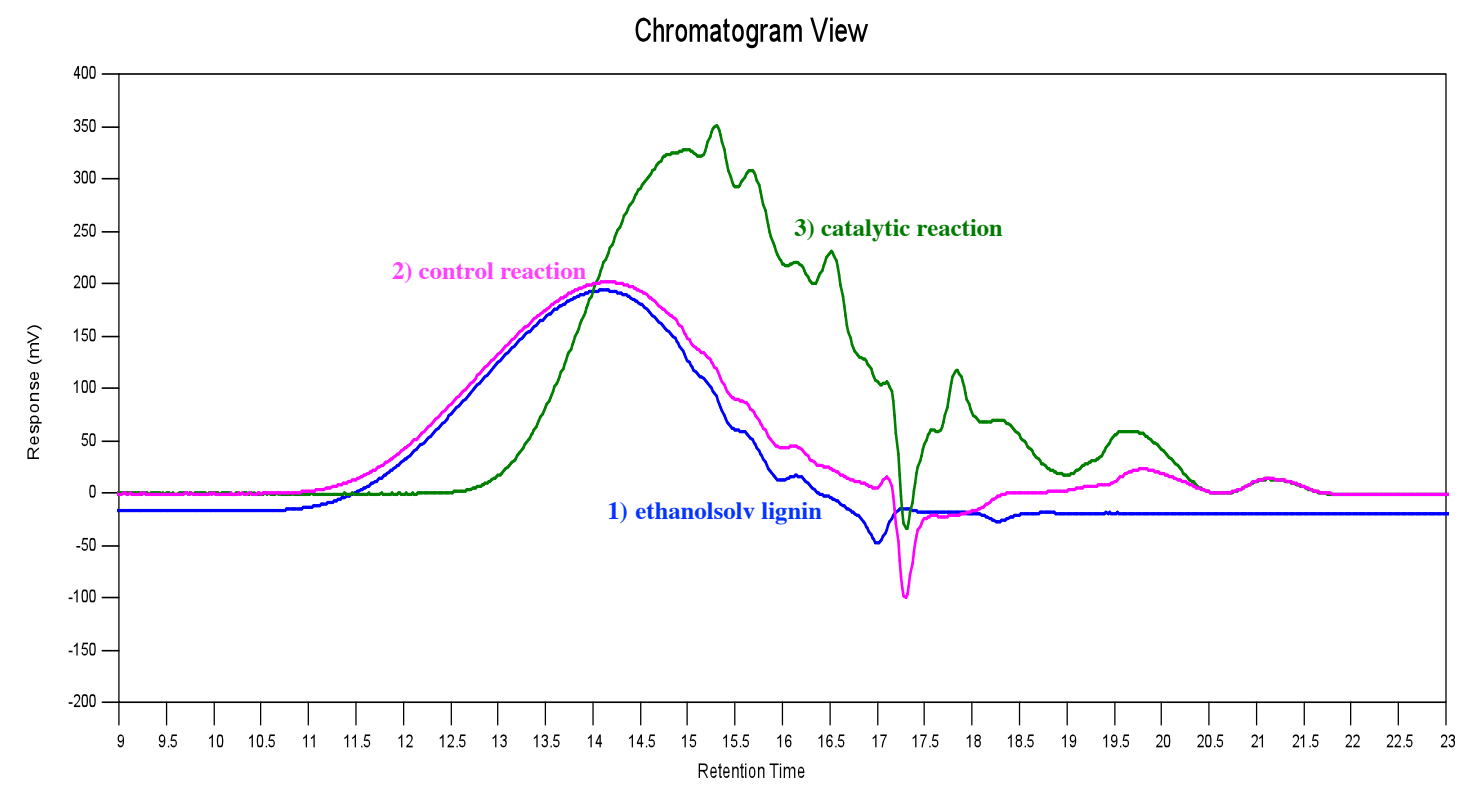

Figure S9. GPC graphs of 1) ethanolsolv lignin, 2) material obtained from the control experiment and 3) degraded ethanolsolv lignin after fragmentation reaction

\section{The procedure for $\mathrm{Pd} / \mathrm{C}$ catalyzed fragmentation of dioxanesolv lignin under an atmospheric pressure of hydrogen (Figure 2 and Entry 3, Table 2)}

The reaction was conducted according to the general procedure with $\mathrm{Pd} / \mathrm{C}(63.9 \mathrm{mg}$, $6.00 \times 10^{-2} \mathrm{mmol}, 20.0 \mathrm{~mol} \%$ ), dioxanesolv lignin (59.4 mg, $\left.0.300 \mathrm{mmol}\right)$, dioxane (1.2 $\mathrm{ml})$ and $\mathrm{H}_{2}(15 \mathrm{psi})$ at $200{ }^{\circ} \mathrm{C}$ for $24 \mathrm{~h}$. The resulting dark brown oily film $(40.9 \mathrm{mg}, 69 \%$ yield of recovery) was analyzed by HSQC and GPC experiments. GC analysis of the aliquot obtained from the reaction mixture showed the formation of 4-Ethylphenol 19 (0.39 mg), 4-Ethylguaiacol 14 (1.99 mg), 2-Methoxy-4-propylphenol 21 (1.24 mg), 4ethyl-2,6-dimethoxyphenol 20 (2.32 mg), 2,6-dimethoxy-4-propylphenol 22 (1.30 mg), dihydroconiferyl alcohol 23 (0.37 mg), and 4-(3-Hydroxypropyl)-2,6-dimethoxyphenol $24(0.40 \mathrm{mg})$ in combined $13.5 \mathrm{wt} \%$ yield.

A control experiment was conducted exactly as described above except for the exclusion of $\mathrm{Pd} / \mathrm{C}$ catalyst in the reaction. A dark brown solid was obtained $(57.1 \mathrm{mg}, 96 \%$ yield of recovery), analyzed by HSQC and GPC experiments and the data was used for comparison purposes (cf. Figure 2 in the main text). 


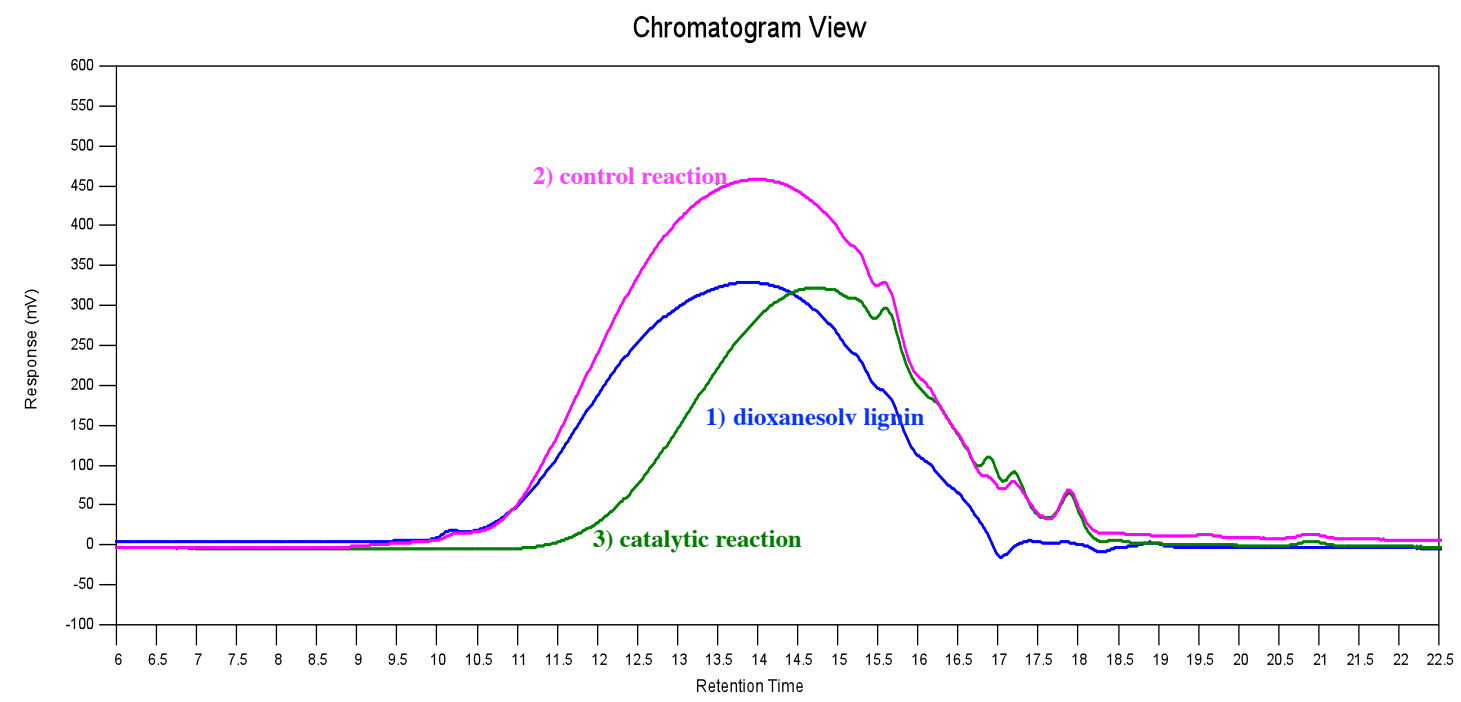

Figure S10. GPC graphs of 1) dioxanesolv lignin, 2) material obtained from the control experiment and 3) degraded dioxanesolv lignin after fragmentation reaction

The procedure for $\mathrm{Pd} / \mathrm{C}$ catalyzed fragmentation of dioxanesolv pine lignin under an atmospheric pressure of hydrogen (Figure 2 and Entry 4, Table 2)

The reaction was conducted according to the general procedure with $\mathrm{Pd} / \mathrm{C}(63.9 \mathrm{mg}$, $6.00 \times 10^{-2} \mathrm{mmol}, 20.0 \mathrm{~mol} \%$ ), dioxanesolv pine lignin (59.4 mg, $\left.0.300 \mathrm{mmol}\right)$, dioxane (1.2 ml) and $\mathrm{H}_{2}(15 \mathrm{psi})$ at $200{ }^{\circ} \mathrm{C}$ for $24 \mathrm{~h}$. The resulting dark brown oily film (46.9 $\mathrm{mg}$, $79 \%$ yield of recovery) was analyzed by HSQC and GPC. GC analysis of the aliquot obtained from the reaction mixture showed that 4-ethylphenol 19 (0.38 mg), 4ethylguaiacol 14 (3.27 mg), 2-methoxy-4-propylphenol 21 (0.99 mg), 4-ethyl-2,6dimethoxyphenol 20 (<0.05 mg), 2,6-dimethoxy-4-propylphenol $22 \quad(<0.05 \mathrm{mg})$, dihydroconiferyl alcohol 23 (0.83 mg), and 4-(3-hydroxypropyl)-2,6-dimethoxyphenol 24 $(<0.05 \mathrm{mg})$ formed in a combined yield of $9.3 \mathrm{wt} \%$.

A control experiment was conducted exactly as described above except for the exclusion of the $\mathrm{Pd} / \mathrm{C}$ catalyst in the reaction. A dark brown solid was obtained $(59.1 \mathrm{mg},>99 \%$ yield of recovery). The solid was analyzed by HSQC and GPC, and the data were used for comparison purposes (cf. Figure 2 in the main text). 


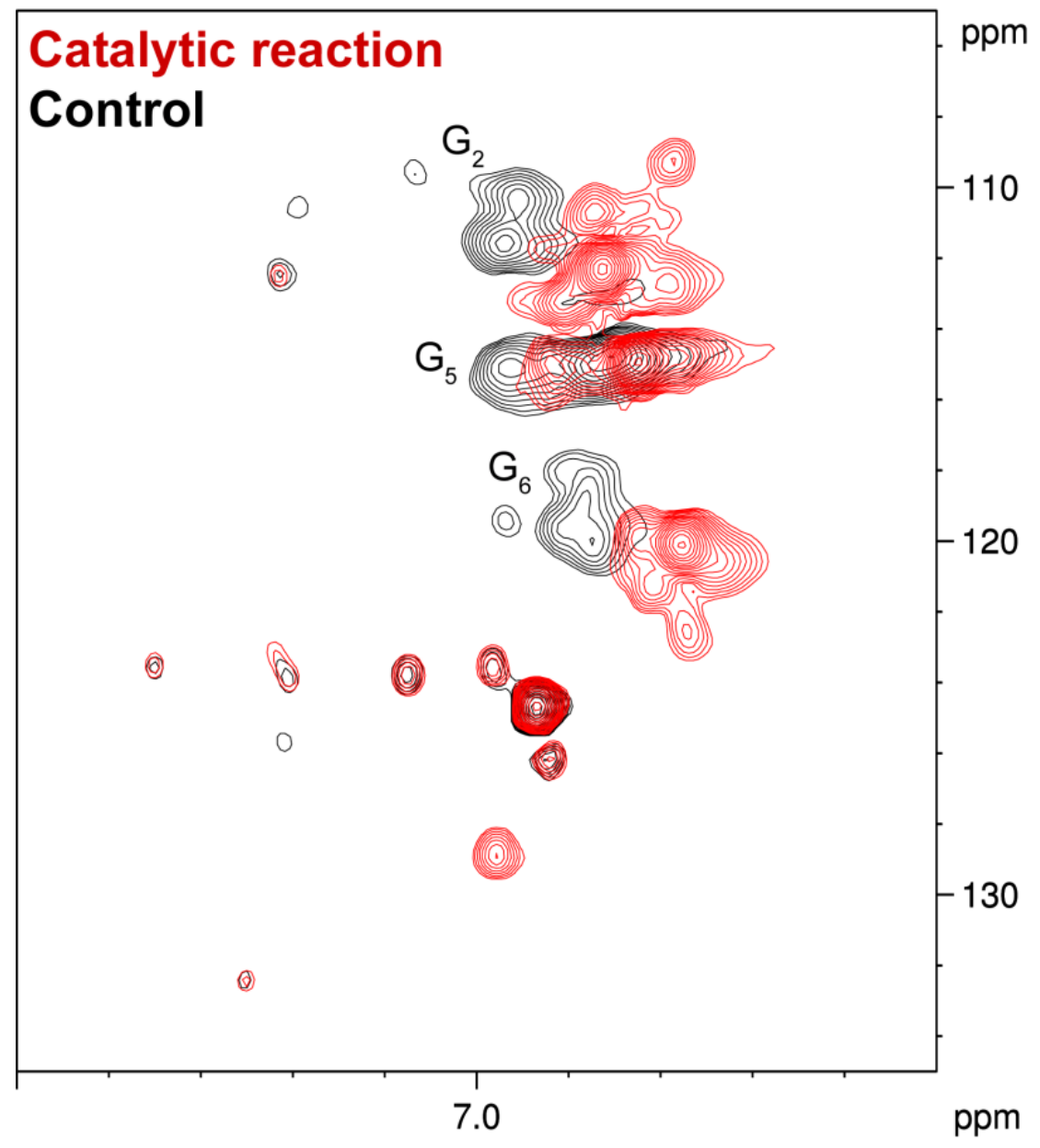

Pine lignin has dominant $G$ unit; the catalytic reaction generated alkyl chains<smiles>CCOc1ccc(C(O)C(C)(C)C)cc1OC</smiles>

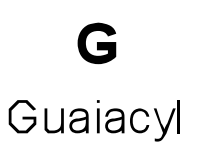<smiles>CCC1=C[C][13CH]=C1</smiles><smiles>CCCC1=C[C][13CH]=CC1</smiles>

Figure S11. HSQC spectra of the degraded dioxanesolv pine lignin and of the material obtained from the control experiment (aromatic region) 


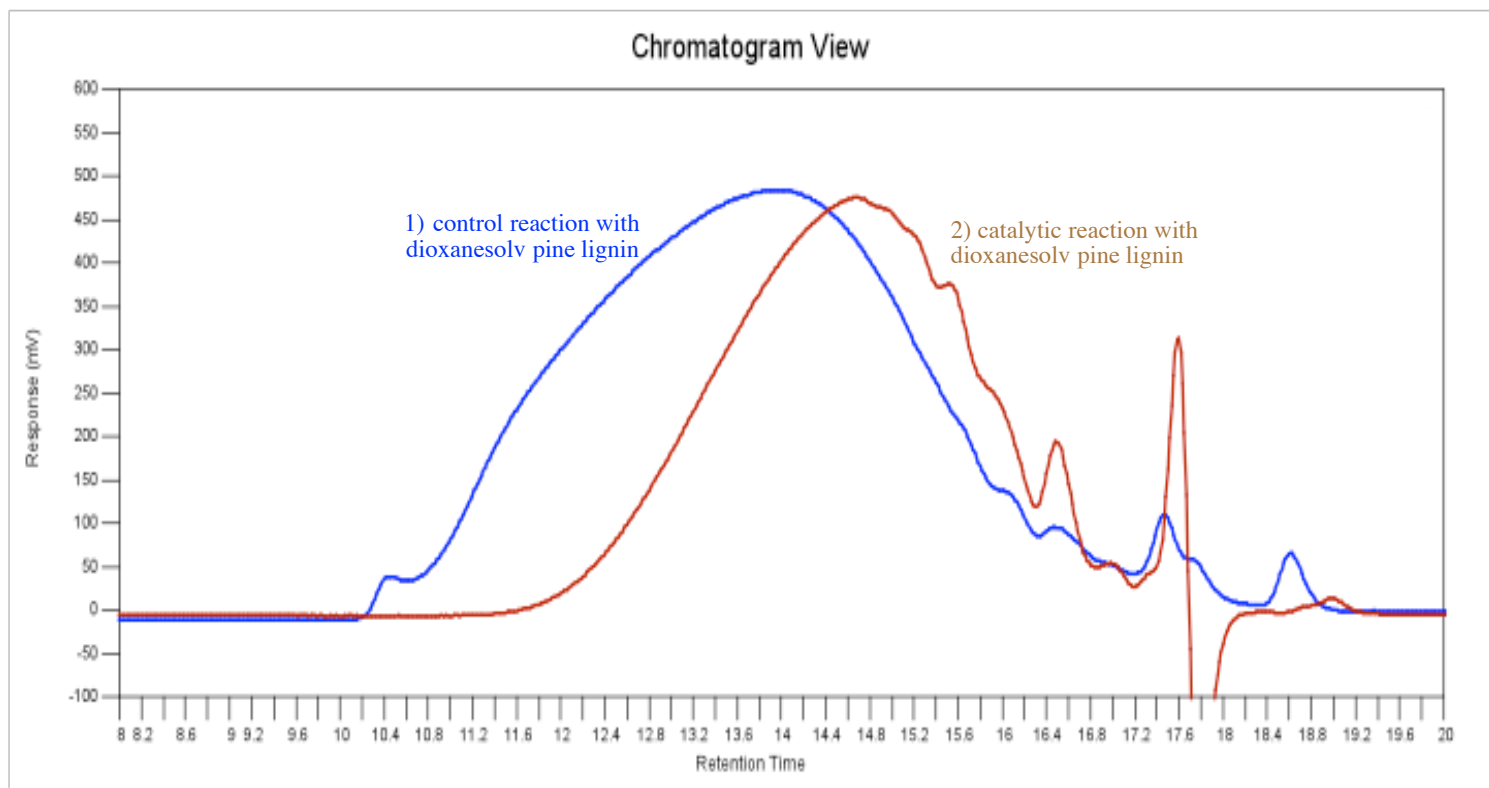

Figure S12. GPC graphs of 1) material obtained from the control experiment and 2) degraded dioxanesolv pine lignin after the fragmentation reaction

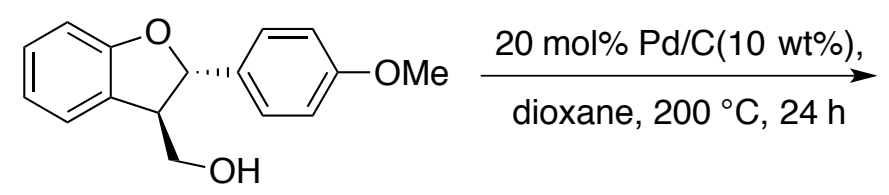

S1

$$
\mathrm{Ar}=\mathrm{p}-\mathrm{OMePh}
$$<smiles>COc1ccc([C@@H]2Oc3ccccc3[C@H]2CO)cc1</smiles>

S1 $\underset{\mathrm{H}_{2} \text {, dioxane, } 200^{\circ} \mathrm{C}, 24 \mathrm{~h}}{\stackrel{20 \mathrm{~mol} \% \mathrm{Pd} / \mathrm{C}(10 \mathrm{wt} \%)}{\longrightarrow}}$<smiles>Cc1c([Se])oc2ccccc12</smiles>

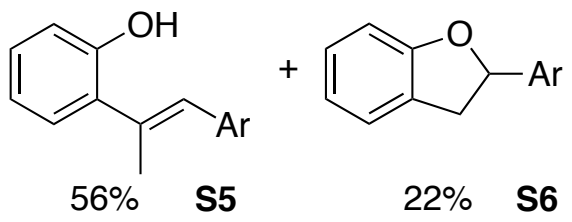<smiles>Oc1ccccc1C(=CBr)[15N]=[Te]</smiles><smiles>OC[C@H](C[17Br])c1ccccc1O</smiles>
$\sim 60 \% \quad$ S7 + numerous other products

Scheme S1. Fragmentation of the phenylcoumaran model compound with and without 15 psi of hydrogen

The procedure for $\mathrm{Pd} / \mathrm{C}$ catalyzed fragmentation of the phenylcoumaran model compound under an atmospheric pressure of hydrogen 
The reaction was conducted according to the general procedure with $\mathrm{Pd} / \mathrm{C}(63.9 \mathrm{mg}$, 6.00x $\left.10^{-2} \mathrm{mmol}, \quad 20.0 \mathrm{~mol} \%\right)$, (2-(4-methoxyphenyl)-2,3-dihydrobenzofuran-3yl)methanol (S1, $76.9 \mathrm{mg}, 0.300 \mathrm{mmol})$, dioxane $(1.2 \mathrm{ml})$ and $\mathrm{H}_{2}(15 \mathrm{psi})$ at $200{ }^{\circ} \mathrm{C}$ for $24 \mathrm{~h}$. The resulting clear light yellow oil (69.2 $\mathrm{mg}, 90 \%$ yield of recovery) was analyzed by ${ }^{1} \mathrm{H}$ NMR spectroscopy. The crude ${ }^{1} \mathrm{H}$ NMR analysis showed that $\mathbf{S} 7$ formed in $60 \%$ yield as the major identifiable product. ${ }^{11}$ About $15 \%$ of $\mathbf{S 5}$ also formed (nitrobenzene as the internal standard). In addition, many unidentifiable byproducts formed, as observed in the baseline of the crude ${ }^{1} \mathrm{H}$ NMR spectrum at $>98 \%$ conversion of the phenylcoumaran model substrate.

An experiment was conducted exactly as described above, except for the exclusion of 15 psi of hydrogen in the reaction. The hydrogen was substituted by an atmospheric pressure of nitrogen. A clear, light yellow oil was obtained (73.8 mg, 96\% yield of recovery) and analyzed by ${ }^{1} \mathrm{H}$ NMR spectroscopy. The crude ${ }^{1} \mathrm{H}$ NMR analysis showed the formation of $\mathbf{S 3}$ in $8 \%$ yield, $\mathbf{S 4}$ in 14\% yield, $\mathbf{S 5}$ in 56\% yield and $\mathbf{S 6}$ in 22\% yield with added nitrobenzene as the internal standard. Greater than $98 \%$ conversion of the phenylcoumaran model substrate was observed.<smiles>COc1ccc(C2OCC3C(c4ccc(OC)cc4)OCC23)cc1</smiles>

S2<smiles>COc1ccc(C2OCC3C(c4ccc(OC)cc4)OCC23)cc1</smiles>

S2

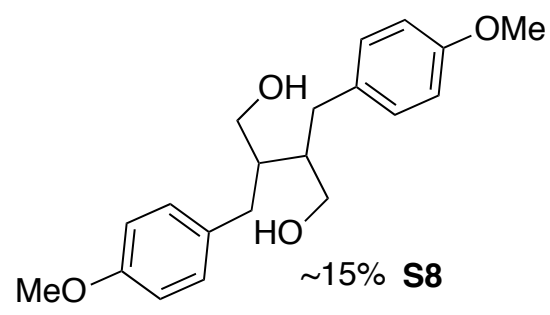

+ numerous other products in small quantities<smiles>COc1ccc(CC(CO)C(CO)Cc2ccc(OC)cc2)cc1</smiles>

+ numerous other products in small quantities

Scheme S2. Fragmentation of resinol model compound with and without 15 psi of hydrogen 


\section{The procedure for $\mathrm{Pd} / \mathrm{C}$ catalyzed fragmentation of the resinol model molecule under an atmospheric pressure of hydrogen}

The reaction was conducted according to the general procedure with $\mathrm{Pd} / \mathrm{C}(63.9 \mathrm{mg}$, $\left.6.00 \times 10^{-2} \mathrm{mmol}, 20.0 \mathrm{~mol} \%\right)$, 1,4-Bis(4-methoxyphenyl)tetrahydro- $1 H, 3 H$-furo[3,4c] furan $(\mathbf{S 2}, 97.9 \mathrm{mg}, 0.300 \mathrm{mmol})$, dioxane $(1.2 \mathrm{ml})$ and $\mathrm{H}_{2}(15 \mathrm{psi})$ at $200{ }^{\circ} \mathrm{C}$ for $24 \mathrm{~h}$. The resulting clear light yellow oil $\left(86.2 \mathrm{mg}, 88 \%\right.$ yield of recovery) was analyzed by ${ }^{1} \mathrm{H}$ NMR spectroscopy. The crude ${ }^{1} \mathrm{H}$ NMR analysis showed that $\mathbf{S 8}$ formed in $50 \%$ yield as the major identifiable product ${ }^{12}$ with added nitrobenzene as the internal standard. In addition, many unidentifiable byproducts formed, as observed in the baseline of the crude ${ }^{1} \mathrm{H}$ NMR spectrum at $>98 \%$ conversion of the resinol model substrate.

An experiment was conducted exactly as described above, except for the exclusion of 15 psi of hydrogen in the reaction. The hydrogen was replaced by an atmospheric pressure of nitrogen. A clear light yellow oil was obtained $(91.0 \mathrm{mg}, 93 \%$ yield of recovery) and analyzed by ${ }^{1} \mathrm{H}$ NMR spectroscopy. The crude ${ }^{1} \mathrm{H}$ NMR analysis showed that $\mathbf{S 8}$ formed in $15 \%$ yield as the major identifiable product with added nitrobenzene as the internal standard. In addition, many unidentifiable byproducts formed, as observed in the baseline of the crude ${ }^{1} \mathrm{H}$ NMR spectrum at $90 \%$ conversion of the resinol model substrate.

\section{General procedure for the gram-scale catalytic fragmentation of lignin samples under an atmospheric pressure of hydrogen with reduced loading of $\mathrm{Pd} / \mathrm{C}$}

In a glovebox, a $250 \mathrm{ml}$ Schlenk vessel equipped with a Teflon screw valve was charged with $10 \mathrm{wt} \% \mathrm{Pd} / \mathrm{C}(0.80 \mathrm{~g}, 0.75 \mathrm{mmol}$ of pure palladium, $5.0 \mathrm{~mol} \%)$, a lignin sample $(3.0$ $\mathrm{g}, 15 \mathrm{mmol})$ and a magnetic stir bar. Then, dioxane $(30 \mathrm{ml})$ was added, and the mixture was stirred for $5 \mathrm{~min}$ to dissolve the lignin. The Schlenk vessel was sealed with the Teflon screw valve and removed from the glovebox. The reaction mixture was degassed via three cycles of freeze-pump-thaw, and the vessel was pressurized with 1 bar (15 psi) of hydrogen at room temperature. The vessel was sealed with the Teflon valve and heated in an oil bath at $180^{\circ} \mathrm{C}$ for $24 \mathrm{~h}$. The resulting dark black mixture was cooled to room temperature, diluted with additional dioxane $(30 \mathrm{ml})$, and filtered through a glass frit covered with a bed of Celite under vacuum to remove black solid materials. Additional 
portions of dioxane $(3 \times 10 \mathrm{~mL})$ were used to wash the Celite, and the filtrates were combined to give a clear dark brown solution. The volatile materials were evaporated under vacuum, and the resulting dark black residue was subjected to high vacuum $(<50$ torr) for at least $48 \mathrm{~h}$ to remove the remaining volatile compounds. A dark brown oily gel (90-97\% yield of recovery) resulted. The dark brown material was characterized by GPC and subjected to viscosity measurements.

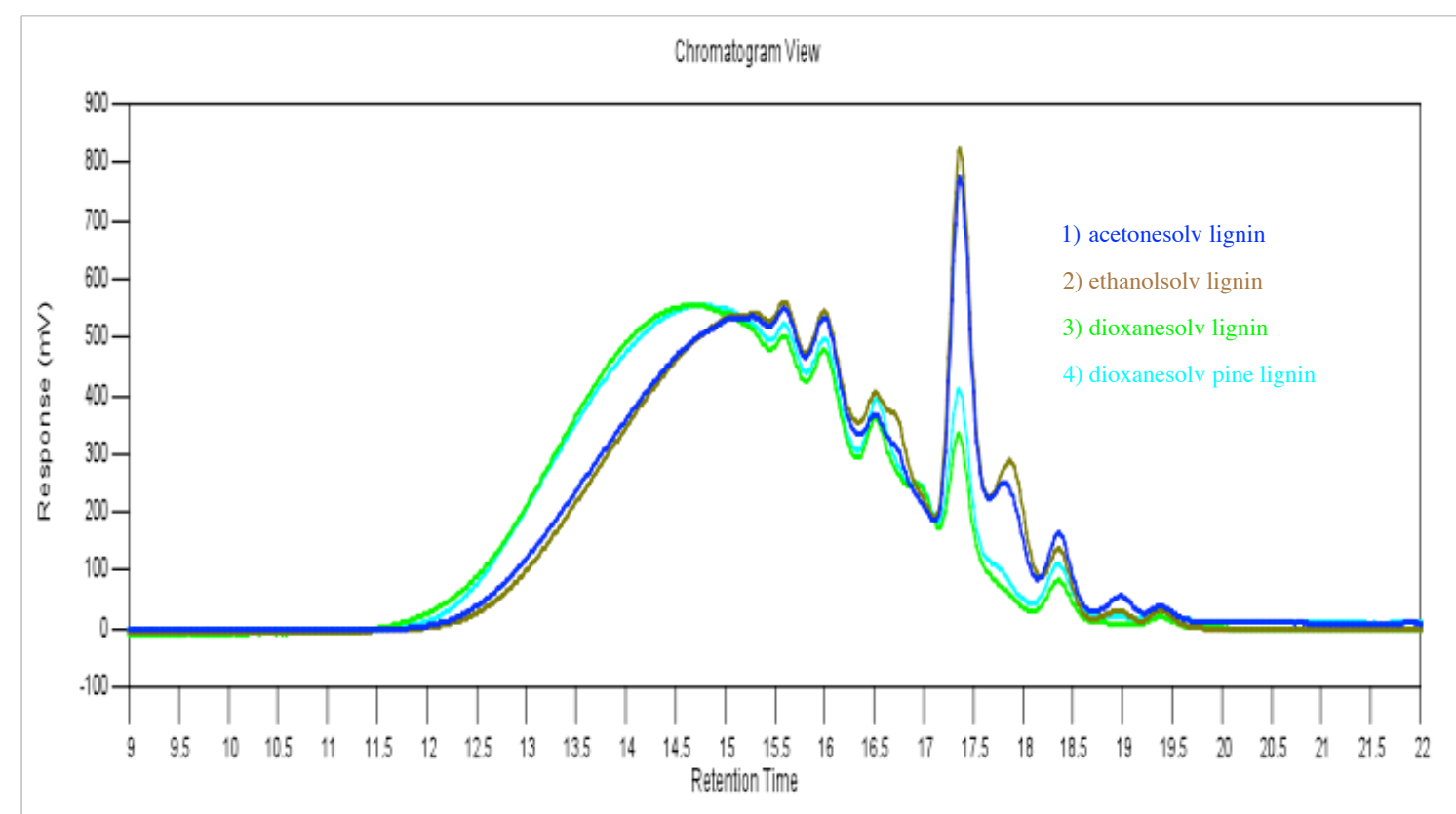

Figure S13. GPC graphs of gram-scale fragmentations of 1) acetonesolv lignin, 2) ethanolsolv lignin, 3) dioxanesolv lignin and 4) dioxanesolv pine lignin 
Table S2. Viscosity measurement of dioxansolv lignin blended with various amount of dioxane at 22 and $50{ }^{\circ} \mathrm{C}$

\begin{tabular}{lccc} 
Entry & Dioxane $(\mathrm{mg} / 100 \mathrm{mg}$ of sample) & $\mathrm{T}\left({ }^{\circ} \mathrm{C}\right)$ & Viscosity $(\mathrm{cP})$ \\
\hline 1 & 0 & 22 & $>1000$ \\
2 & 0 & 50 & $>1000$ \\
\hline 3 & 20 & 22 & 440.7 \\
4 & 40 & 22 & 128.9 \\
5 & 60 & 22 & 37.5 \\
6 & 80 & 22 & 18.3 \\
7 & 20 & 50 & 305.1 \\
8 & 40 & 50 & 70.7 \\
9 & 60 & 50 & 19.1 \\
10 & 80 & $\mathbf{5 0}$ & $\mathbf{9 0 . 8}$ \\
\hline
\end{tabular}

Table S3. Viscosity measurement of dioxansolv lignin blended with various renewable solvents

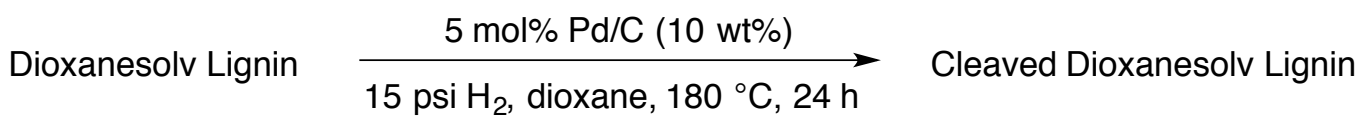

$\begin{array}{ll}3.6 \text { gram in } 50 \mathrm{~mL} \text { dioxane } & 3.6 \mathrm{~g} \text { in } 2.9 \mathrm{~g} \mathrm{1,4-dioxane,} \\ & \text { viscosity: } 18.3 \mathrm{cP} \text { at } 22{ }^{\circ} \mathrm{C}\end{array}$

\begin{tabular}{|c|c|}
\hline Cleaved Dioxanesolv Lignin & Cleaved Dioxanesolv Lignin \\
\hline $\begin{array}{l}3.6 \mathrm{~g} \text { in } 4.8 \mathrm{~g} \text { 2-MeTHF, } \\
\text { viscosity: } 16.9 \mathrm{cP} \text { at } 22{ }^{\circ} \mathrm{C}\end{array}$ & $\begin{array}{l}3.6 \mathrm{~g} \text { in } 2.9 \mathrm{~g} \text { 2-hydroxymethylTHF, } \\
\text { viscosity: } 20.4 \mathrm{cP} \text { at } 22^{\circ} \mathrm{C}\end{array}$ \\
\hline Cleaved Dioxanesolv Lignin & Cleaved Dioxanesolv Lignin \\
\hline $\begin{array}{l}3.6 \mathrm{~g} \text { in } 2.9 \mathrm{~g} 2,5 \text {-hydroxymethylTHF, } \\
\text { viscosity: } 26.7 \mathrm{cP} \text { at } 22^{\circ} \mathrm{C}\end{array}$ & $\begin{array}{l}3.6 \mathrm{~g} \text { in } 2.9 \mathrm{~g} \gamma \text {-valerolactone, } \\
\text { viscosity: } 13.2 \mathrm{cP} \text { at } 22^{\circ} \mathrm{C}\end{array}$ \\
\hline
\end{tabular}


${ }^{1} \mathrm{H}$ NMR (300 MHz, $\left.\mathrm{CDCl}_{3}\right)$ : (2-(4-methoxyphenyl)-2,3-dihydrobenzofuran-3yl)methanol (S1)<smiles>COc1ccc(C2Oc3ccccc3C2CO)cc1</smiles>

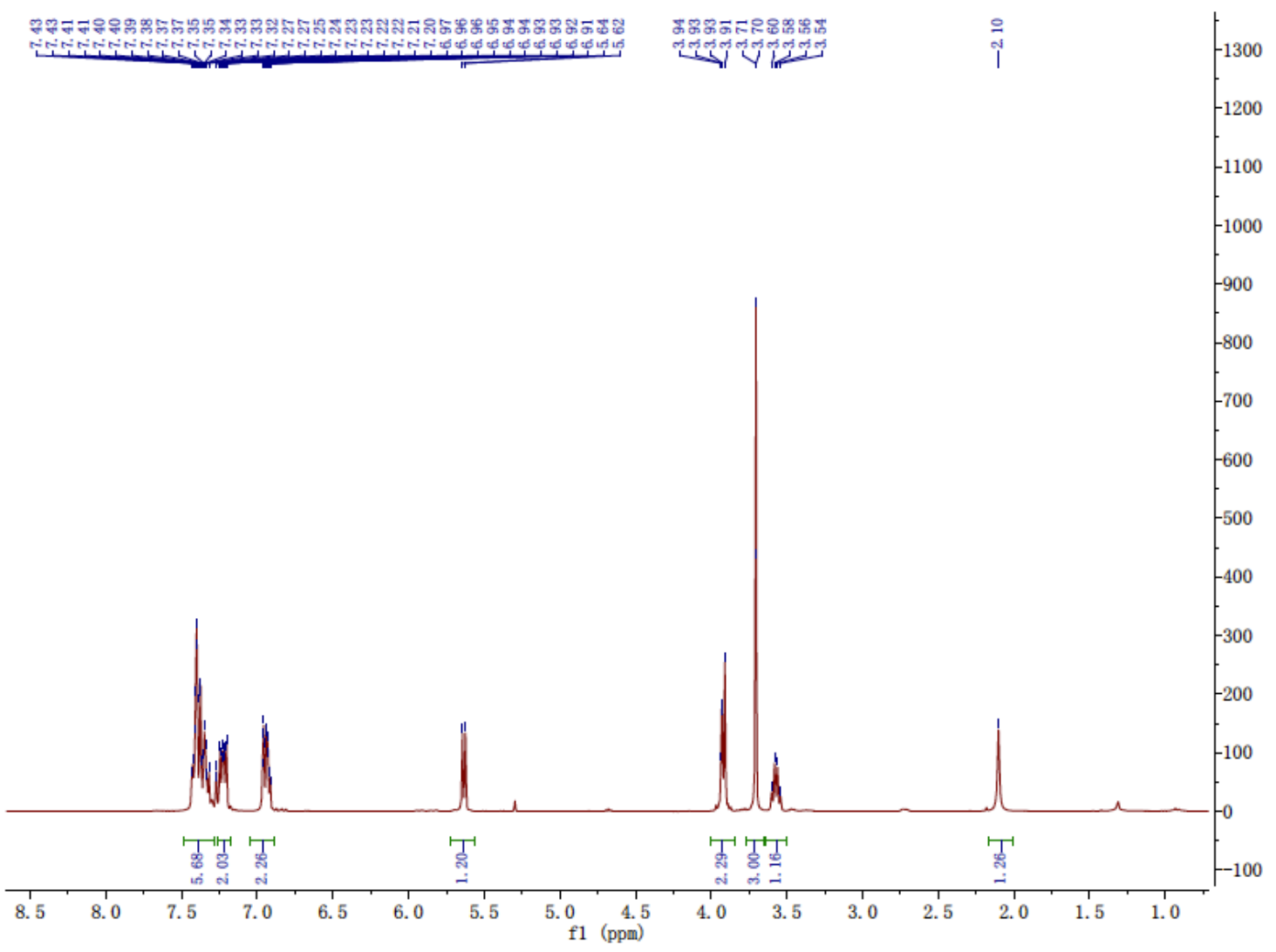


${ }^{13} \mathrm{C}\left\{{ }^{1} \mathrm{H}\right\}$ NMR (125 MHz, $\mathrm{CDCl}_{3}$ ): (2-(4-methoxyphenyl)-2,3-dihydrobenzofuran-3yl)methanol (S1)<smiles>COc1ccc(C2Oc3ccccc3C2CO)cc1</smiles>

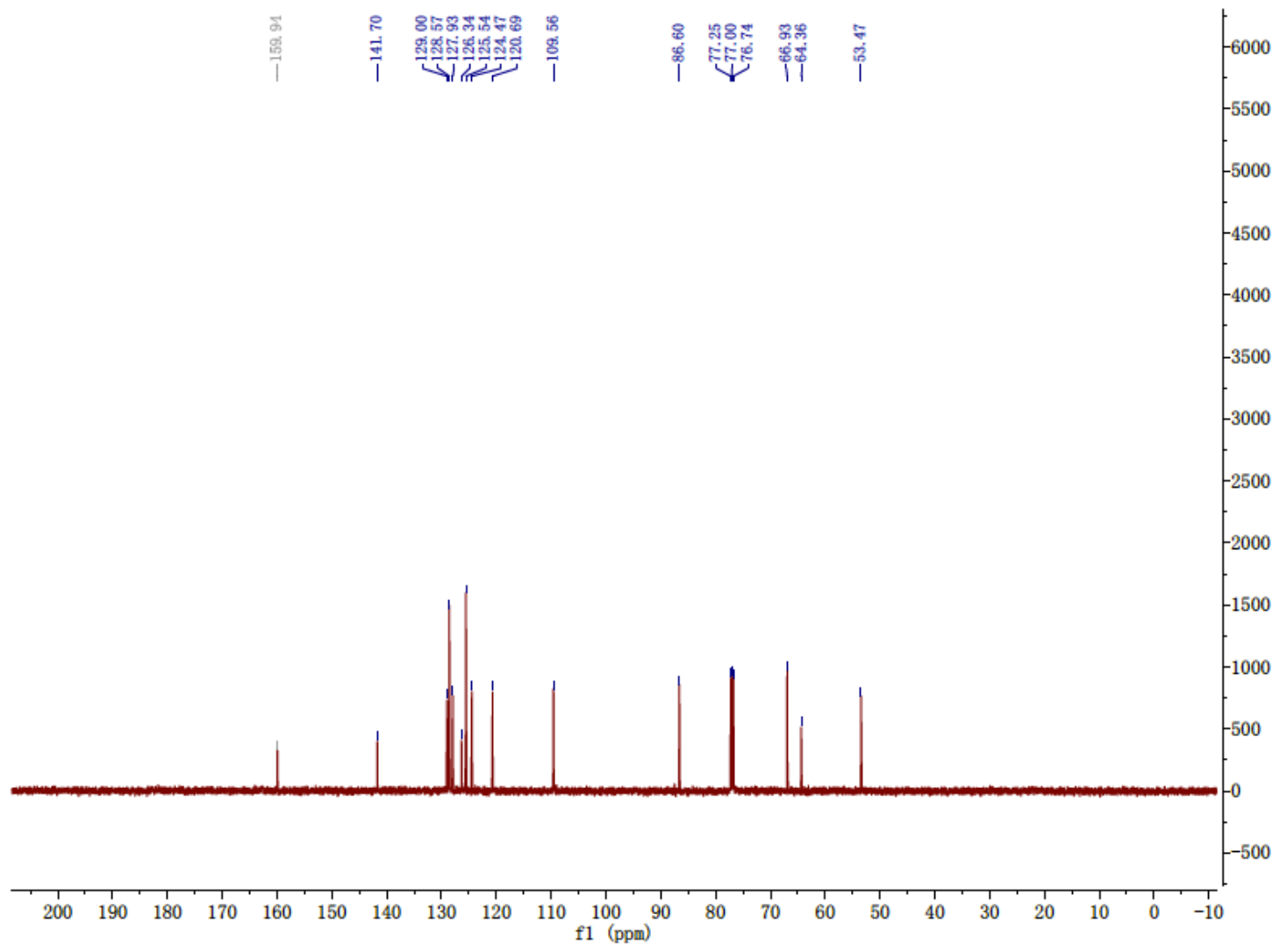


${ }^{1} \mathrm{H}$ NMR (300 MHz, $\mathrm{CDCl}_{3}$ ): 1,4-bis(4-methoxyphenyl)tetrahydro-1 $H, 3 H$-furo[3,4c]furan (S2)<smiles>COc1ccc(C2OCC3C(c4ccc(OC)cc4)OCC23)cc1</smiles>

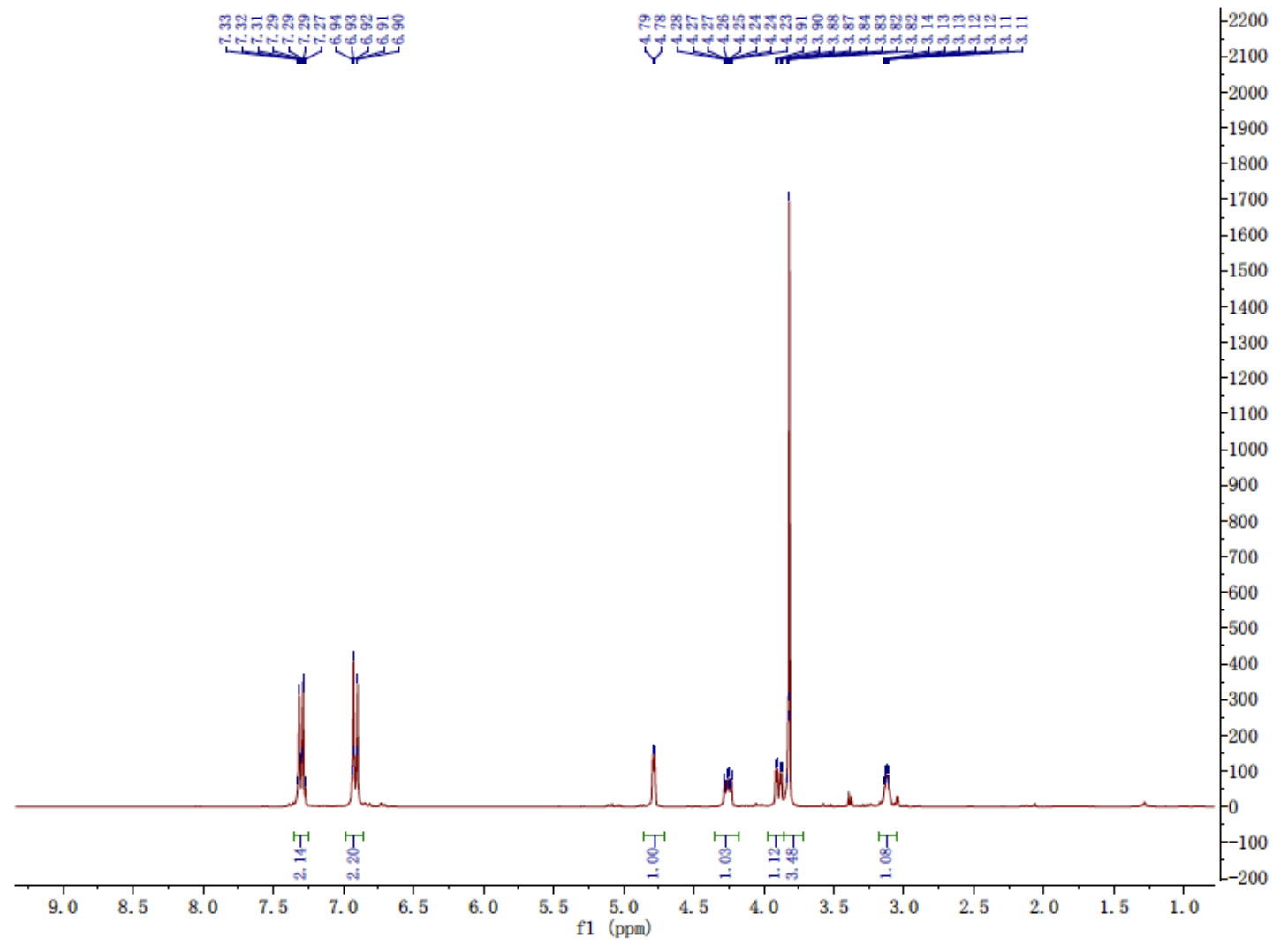


${ }^{13} \mathrm{C}\left\{{ }^{1} \mathrm{H}\right\}$ NMR (125 MHz, $\left.\mathrm{CDCl}_{3}\right):$ 1,4-bis(4-methoxyphenyl)tetrahydro-1 $\mathrm{H}, 3 \mathrm{H}$ furo[3,4-c]furan (S2)<smiles>COc1ccc(C2OCC3C(c4ccc(OC)cc4)OCC23)cc1</smiles>

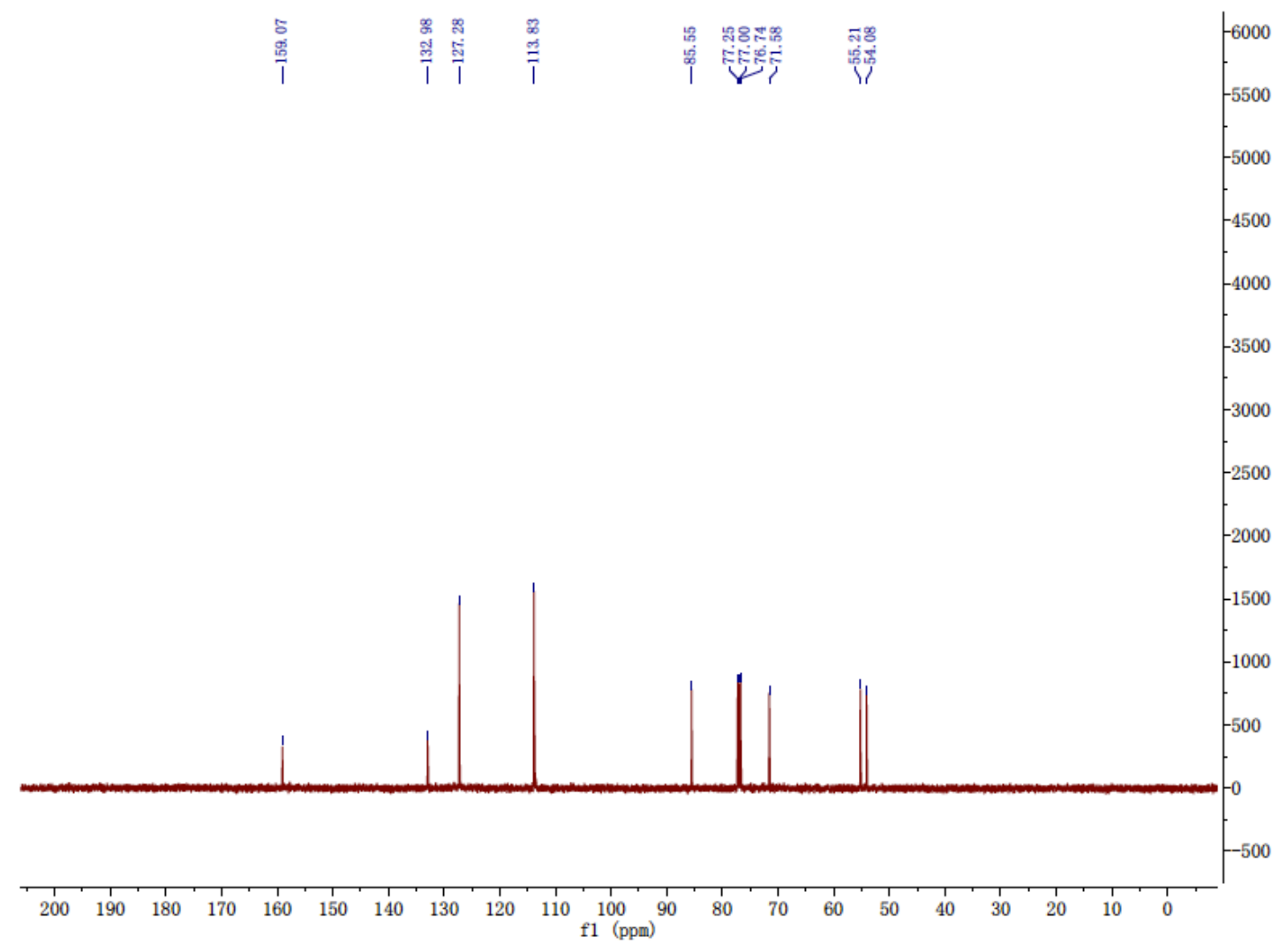




\section{References}

[1] (a) Villaverde, J. J.; Li, J.; Ek, M.; Ligero, P.; Vega, A. J. Agric. Food Chem. 2009, 57, 6262. (b) Rencoret, J.; Gutiérrez, A.; Nieto, L.; Jiménez-Barbero, J.; Faulds, C. B.; Kim, H.; Ralph, J.; Martínez, A. T.; del Río, J. C. Plant Physiol. 2011, 155, 667.

[2] Gao, F.; Webb, J. D.; Hartwig, J. F. Angew. Chem., Int. Ed. 2016, 55, 1474.

[3] Nichols, J. M.; Bishop, L. M.; Bergman, R. G.; Ellman, J. A. J. Am. Chem. Soc. 2010, $132,12554$.

[4] Wu, A.; Patrick, B. O.; Chung, E.; James, B. R. Dalton Trans. 2012, 41, 11093.

[5] Buendia, J.; Mottweiler, J.; Bolm, C. Chem. Eur. J. 2011, 17, 13877.

[6] Chan, J. M. W.; Bauer, S.; Sorek, H.; Sreekumar, S.; Wang, K.; Toste, F. D. ACS Catal. 2013, 3, 1369.

[7] Jung, J.-C.; Park, O.-S. Synthetic Communications 2007, 37, 1665.

[8] Fischer, J.; Savage, G. P.; Coster, M. J. Org. Lett. 2011, 13, 3376.

[9] Reale, S.; Attanasio, F.; Spreti, N.; De Angelis, F. Chem. Eur. J. 2010, 16, 6077.

[10] Bauer, S.; Sorek, H.; Mitchell, V. D.; Ibáñez, A. B.; Wemmer D. E. J. Agric. Food Chem. 2012, 60, 8203.

[11] Shaw, S. A.; Aleman, P.; Christy, J.; Kampf, J. W.; Va, P.; Vedejs, E. J. Am. Chem. Soc. 2006, 128, 925.

[12] Belletire, J. L.; Spletzer, E. G.; Pinhas, A. R. Tetrahedron Lett. 1984, 25, 5969. 